\title{
Multiperiod Competitive Supply Chain Networks with Inventorying and A Transportation Network Equilibrium Reformulation
}

\author{
Zugang Liu \\ Department of Business and Economics \\ Pennsylvania State University \\ Hazleton, Pennsylvania 18202 \\ Anna Nagurney \\ Department of Finance and Operations Management \\ Isenberg School of Management \\ University of Massachusetts \\ Amherst, Massachusetts 01003 \\ Optimization and Engineering 13(2): (2012), pp 471-503.
}

\begin{abstract}
In this paper, we present a multitiered dynamic supply chain network equilibrium modeling framework in which the decision-makers have sufficient information about the future and seek to determine their optimal plans that maximize their profits over the multiperiod planning horizon. We construct the finite-dimensional variational inequality governing the equilibrium of the multiperiod competitive supply chain network. The model allows us to investigate the interplay of the heterogeneous decision-makers in the supply chain in a dynamic setting, and to compute the resultant equilibrium pattern of product outputs, transactions, inventories, and product prices. We then establish the supernetwork equivalence of the multiperiod supply chain model with a properly configured transportation network, which provides a new interpretation of the equilibrium conditions of the former in terms of paths and path flows. This framework offers great modeling flexibility so that, for example, transportation delay and/or perishable products can be easily handled, as we also demonstrate. Numerical examples are provided to illustrate how such multiperiod supply chain problems can be reformulated and solved as transportation network equilibrium problems in practice.
\end{abstract}

Key words: supply chains, transportation network, variational inequalities, multiperiod decision-making 


\section{Introduction}

A supply chain is a network of manufacturers, storage facility managers, transporters and retailers that perform the functions of production, storage, transportation, and sale of a particular product. Nowadays, the highly dynamic and competitive business environment makes the decision-making of the supply chain participants increasingly complex. In order to survive and thrive, the business enterprises need to make intelligent and consistent decisions that not only provide optimal decisions today but also benefit them in the future. In this paper, we propose a multitiered, multiperiod supply chain network model which can be utilized to investigate and facilitate the complex decision-making of the supply chain participants in a competitive and dynamic global environment.

The majority of the supply chain management literature has focused primarily on the optimization problems faced by a single decision-maker in the supply chain (cf. Federgruen and Zipkin (1986), Federgruen (1993), Lee and Billington (1993), Slats et al. (1995), Anupindi and Bassok (1996), Bramel and Simchi-Levi (1997), Ganeshan et al. (1998), Stadtler and Kilger (2000), Miller (2001), Mentzer (2001), Hensher et al. (2001)).

In today's business environment no firm is isolated. It is an imperative for managers to consider the behaviors of competitors as well as the cooperation with upstream and downstream partners. Therefore, more recently, both the analysis and the computation of equilibria have become major topics of supply chain research. For example, Lederer and Li (1997) modeled the competition between firms that provide products or services to the customers who are sensitive to the delay-time. Cachon and Zipkin (1999) studied inventorying decision-making in a two stage serial supply chain. Corbett and Karmarkar (2001) investigated a supply chain network consisting of several tiers of decision-makers and provided a framework for comparing a variety of supply chain structures. Bernstein and Federgruen (2003), in turn, modeled retail market competition in the case of a single supplier and multiple retailers in a multiperiod setting. The book chapter by Cachon and Netessine (2003) overviews applications of game theory to supply chain modeling and analysis. See also the reviews by Leng and Parlar (2005) and Nagarajana and Soic (2008), as well as the annotated bibliography on network optimization in supply chains and financial engineering by Geunes and Pardalos (2003).

Equilibrium computation using continuous and discrete variational inequality models has 
also been widely studied and applied to various issues in supply chains. Nagurney et al. (2002) proposed the first supply chain network equilibrium model, which was multitiered and involved competition among decision-makers in a given tier, but cooperation between tiers of decision-makers, consisting of manufacturers, retailers, and consumers at the demand markets. The governing equilibrium conditions were formulated as a finite-dimensional variational inequality problem. Recently, it was shown by Nagurney (2006a) that this supply chain network problem can be reformulated and solved as a transportation network equilibrium problem in paths and path flows, which has opened up the study of supply chains through the prism of transportation networks, a subject with a much longer history and literature. Nagurney et al. (2005) investigated the impact of the supply side and demand side risk on multitiered supply chain networks. Cruz and Wakolbinger (2008) investigated the multiperiod effects of corporate social responsibility on supply chain networks, transaction costs, emissions, and risk.

Liu and Nagurney (2009), in turn, developed an integrated electric power supply chain and fuel market framework that considered both economic transactions and physical transmissions of electric power. The authors also utilized the modeling framework to conduct a case study based on the data of the New England electric power supply chain. For more research in this area, see Friesz et al. (2006), Cruz (2008), Hammond and Beullens (2007), Zhang (2006), and Hsueh and Chang (2008). The book by Nagurney (2006b) describes the numerous applications of multitiered network problems with a supply chain foundation, ranging from a variety of static and dynamic supply chains to electric power generation and distribution networks as well as to financial networks with intermediation, with a focus on their relationships to transportation network equilibrium problems. Our paper contributes to this research theme, and extends the literature in this area to a multiperiod (and multitiered) setting. Moreover, our model provides a flexible framework which can incorporate important issues in supply chains such as long lead times (Walker (1999) and Sen (2008)) and perishable product requirements (Hou (2006) and Balkhi and Benkherouf (2004)) as we demonstrate using examples.

Beckmann et al. (1956) proposed the first rigorous mathematical treatment of transportation network equilibrium problems in their classic book, Studies in the Economics of Transportation. For additional research highlights in transportation network equilibrium, see Boyce et al. (2005), Florian and Hearn (1995), and the books by Patriksson (1994) and 
Nagurney (1999, 2000).

Interestingly, earlier to the identification of supply chain network problems with transportation network problems, Dafermos and Nagurney (1985) and Dafermos (1986) demonstrated (see also Dafermos and Nagurney (1984a)) that spatial price equilibrium problems (cf. Samuelson (1952) and Takayama and Judge (1971)) could be transformed into transportation network equilibrium problems over appropriately constructed abstract networks, now commonly referred to as supernetworks (see also, e.g., Nagurney and Dong (2002)). Subsequently, Nagurney and Aronson (1988) developed a multiperiod spatial pricing equilibrium model where inventorying and backordering were allowed at both the supply markets and the demand markets. Nagurney and Aronson (1989) then extended that research and presented a general dynamic spatial price equilibrium model with gains and losses which was capable of handling directly agriculture markets with perishable commodities as well as financial markets.

In this paper, we develop a multiperiod competitive supply chain network equilibrium model in which the manufacturers, the retailers, and the consumers associated with the demand markets are located at distinct tiers of the network, and decisions are made in discrete time periods over a finite planning horizon. The manufacturers produce a homogenous product and sell to the retailers. We assume that each manufacturer has sufficient information about the future, and seeks the optimal production, transaction, and inventory plan in order to maximize his total profit over the planning horizon. We also assume that the manufacturers compete in a noncooperative manner in the sense of Nash $(1950,1951)$.

The retailers, in turn, purchase the products from the manufacturers and sell to the consumers at the demand markets. Each retailer seeks the optimal replenishment and inventory plan to maximize his profit over the planning horizon. We assume that the retailers also have sufficient information about the future and compete with other retailers in a noncooperative manner.

Finally, at each time period, the consumers at the various demand markets determine their consumption levels, and take into consideration both the prices charged by the retailers and the unit transaction/transportation costs in making their consumption decisions. We allow the specifications of the demand functions to change in different time periods so that different trends or seasonalities of the demand can be captured. 
The equilibrium state of the multiperiod competitive supply chain network is one where the manufacturers and the retailers achieve optimality over the entire planning horizon, and the equilibrium conditions at the demand markets are satisfied at each period so that no decision-maker has any incentive to alter his decisions. We present the governing equilibrium conditions as a finite-dimensional variational inequality, which, to our knowledge, is the first model that considers the multiperiod decision-making of heterogenous supply chain firms from a network equilibrium perspective. We then prove that this dynamic supply chain network equilibrium model is isomorphic to a properly configured transportation network equilibrium model with elastic demand (cf. Dafermos (1982) and Dafermos and Nagurney (1984b)). This mathematical equivalence provides a new economic interpretation for the multiperiod supply chain network equilibrium in terms of paths and path flows, and also allows us to transfer the methodological tools as well as qualitative results developed for transportation network equilibrium modeling, analysis, and computation to the study of such supply chains. Note that since equilibria for large-scale transportation networks are routinely computed in practice, the results herein also suggest new opportunities for the effective solution of large-scale multiperiod supply chain networks with inventorying.

It is worth noting that there is a stream of research using projected dynamical systems (PDSs), differential variational inequalities (DVIs), or evolutionary variational inequalities (EVIs) to model dynamic network problems through a continuous-time approach. For the theory and applications of PDSs, see Nagurney and Zhang (1996); for that of DVIs and EVIs see, among others, Pang and Stewart (2008, 2009), Friesz et al. (2006), Cojocaru et al. (2005), Cojocaru et al. (2006), Daniele (2006), and Nagurney et al. (2007).

In this paper, we utilize a discrete-time approach for our modeling, analysis and computations, for which the main advantages are as follows. First, in practice, most supply chain decisions are made in discrete time (see Coyle et al. (2008) and Chopra and Meindl (2009)). Hence, multiperiod models are more intuitive and natural for researchers to interpret and for practitioners to understand. Therefore, multiple period models have been broadly used to formulate supply chain decisions (see, for example, Takayama and Judge (1971), Florian and Klein (1975), Kim and Kim (2000), Dogan and Goetschalckx (1999), Bhattacharjee and Ramesh (2000), Demirtas and Ustuna (2000), Fisher et al. (2001), Porkka et al. (2003), Kaminsky and Swaminathan (2004), Yildirim et al. (2005), Perakis and Sood (2006), and See and Sim (2010)). Second, in our paper, the multiple period model allows for a unified 
treatment of inventorying, production, and transportation as explicit network flows, which can be very difficult to achieve using a continuous time approach. Such a unified network flow treatment provides an elegant and flexible framework in which many important and unique features of supply chains can be easily incorporated. For example, we establish the equivalence between the multiperiod supply chain networks and transportation networks which provides a new economic interpretation for the multiperiod supply chain network equilibrium in terms of paths and path flows. As another example, our model can explicitly consider such important issues as long lead times in global supply chains (Walker (1999) and Sen (2008)) and perishable product requirements (Hou (2006) and Balkhi and Benkherouf (2004)) as we demonstrate through examples. These issues may be difficult to handle using a continuous time model.

This paper is organized as follows. In Section 2, we present the multitiered, multiperiod supply chain network model, and provide the finite-dimensional variational inequality governing the equilibrium. In Section 3, we recall the transportation network equilibrium model with elastic demands of Dafermos and Nagurney (1984b), which was also studied by Nagurney and Zhang (1996). In Section 4, we establish that the proposed multiperiod supply chain network equilibrium model of Section 2 can be reformulated as a transportation network equilibrium model as described in Section 3, over a properly constructed abstract network or supernetwork (cf. Nagurney and Dong (2002) and the references therein). We also discuss how this model can capture time delays associated with transportation as well as perishable products. In Section 5, numerical examples of multiperiod supply chain networks are reformulated and solved as transportation networks using algorithms developed for the computation of transportation network equilibria. In Section 6, we present a summary of the results of this paper, along with our conclusions.

\section{The Multiperiod Supply Chain Network Model}

In this section, we develop the multiperiod supply chain network model with elastic demands. The time planning horizon is discretized into periods: $1, \ldots, t, \ldots, T$. The model consists of $m$ manufacturers, $n$ retailers, and $o$ demand markets, as depicted in Figure 1 . We denote a typical manufacturer by $i$, a typical retailer by $j$, and a typical demand market by $k$. In the supply chain network, the links between the tiers represent transportation/transaction links while the links between the adjacent temporal subnetworks represent the inventory links. The majority of the needed notation is shown in Tables 1 and 2. The equilibrium 
Time Periods

1

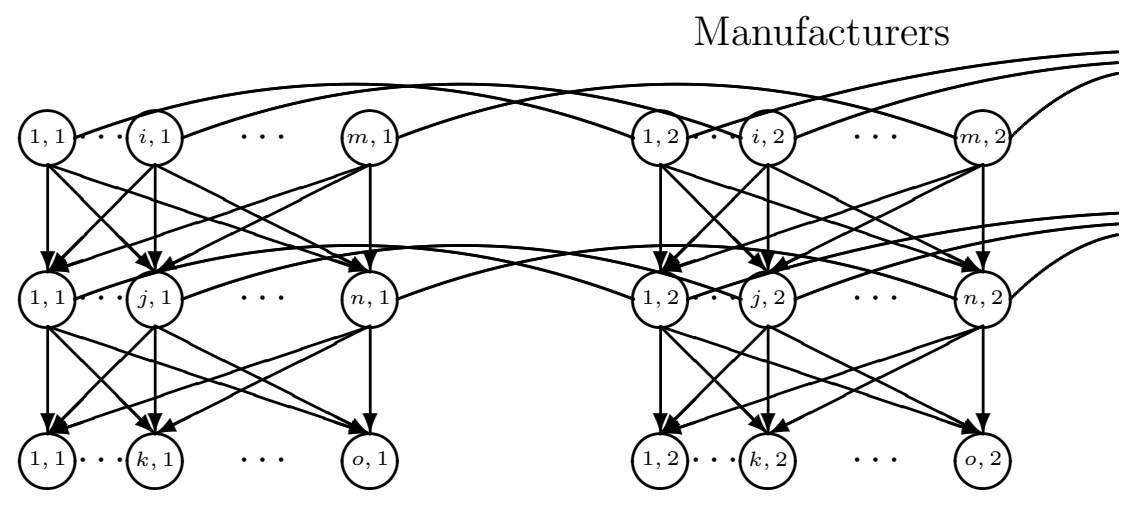

Demand Markets $\begin{array}{ll}\cdots & T\end{array}$

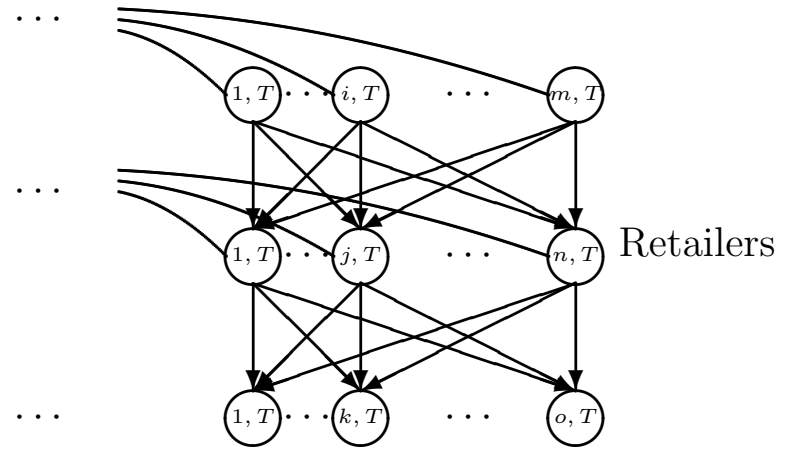

Figure 1: The Network Structure of the Multiperiod Supply Chain

solution is denoted by "**". All vectors are assumed to be column vectors, except where noted.

The top-tiered nodes in Figure 1 represent the $m$ manufacturers in the $T$ time periods with node $(i, t)$ denoting manufacturer $i$ in time period $t$. The manufacturers are the decisionmakers who produce a homogeneous product and sell to the retailers in the second tier of nodes in the supply chain network in Figure 1 . A node $(j, t)$ corresponds to retailer $j$ in time period $t$, where $j=1, \ldots, n$ and $t=1, \ldots, T$.

Both the manufacturers and the retailers can store the product in their inventories with a link joining node $(i, t)$ with node $(i, t+1)$ in Figure 1 corresponding to the inventorying of manufacturer $i$ between time period $t$ and $t+1$ and the link joining node $(j, t)$ with node $(j, t+1)$ corresponding to the inventorying of the product by retailer $j$ from time period $t$ to time period $t+1$. The consumers at the demand markets are represented by the nodes in the bottom tier of the supply chain network and they acquire the product from the retailers. A demand market $k$ at time period $t$ is denoted by node $(k, t)$ with $k=1, \ldots, o$ and $t=1, \ldots, T$.

We first describe the behavior of the manufacturers and then that of the retailers. We, subsequently, discuss the behavior of the consumers at the demand markets. Finally, we 
Table 1: Variables in the Multiperiod Supply Chain Network Equilibrium Model

\begin{tabular}{|c|c|}
\hline Notation & Definition \\
\hline$q$ & $\begin{array}{l}m T \text {-dimensional vector of the manufacturers' production outputs } \\
\text { during the entire planning horizon with component } i t: q_{i t}\end{array}$ \\
\hline$q_{t}$ & $\begin{array}{l}m \text {-dimensional vector of the manufacturers' production outputs } \\
\text { at time period } t \text { with component } i \text { : } q_{i t}\end{array}$ \\
\hline$Q^{1}$ & $\begin{array}{l}m n T \text {-dimensional vector of product flows transacted/shipped between } \\
\text { manufacturers and retailers with component } i j t: q_{i j t}\end{array}$ \\
\hline$Q_{t}^{1}$ & $\begin{array}{l}m n \text {-dimensional vector of product flows transacted/shipped between } \\
\text { manufacturers and retailers at time period } t \text { with component } i j: q_{i j t}\end{array}$ \\
\hline$Q^{2}$ & $\begin{array}{l}\text { noT-dimensional vector of product flows transacted/shipped between retailers and } \\
\text { the demand markets during the entire planning horizon with component } j k t: q_{j k t}\end{array}$ \\
\hline$Q_{t}^{2}$ & $\begin{array}{l}\text { no-dimensional vector of product flows transacted/shipped between retailers and } \\
\text { the demand markets at time period } t \text { with component } j k: q_{j k t}\end{array}$ \\
\hline$h$ & $\begin{array}{l}n T \text {-dimensional vector of the retailers' supplies of the product during the } \\
\text { planning horizon with component } j t: h_{j t}\end{array}$ \\
\hline$h_{t}$ & $\begin{array}{l}n \text {-dimensional vector of the retailers' supplies of the product at time period } t \\
\text { with component } j: h_{j t}\end{array}$ \\
\hline$u^{1}$ & $\begin{array}{l}m T \text {-dimensional vector of the manufacturers' inventory levels during } \\
\text { the planning horizon with component } i t: u_{i t}\end{array}$ \\
\hline$u^{2}$ & $\begin{array}{l}n T \text {-dimensional vector of the retailers' inventory levels during the } \\
\text { planning horizon with component } j t: u_{j t}\end{array}$ \\
\hline$d$ & $o T$-dimensional vector of satisfied market demand with component $k t: d_{k t}$ \\
\hline$\rho_{1}$ & $\begin{array}{l}m n T \text {-dimensional vector of prices charged by the manufacturers in transacting } \\
\text { with the retailers during the entire planning horizon with component } i j t: \rho_{1 i j t}\end{array}$ \\
\hline$\rho_{2}$ & $\begin{array}{l}n T \text {-dimensional vector of prices charged by the retailers during the entire } \\
\text { planning horizon with component } j t: \rho_{2 j t}\end{array}$ \\
\hline$\rho_{3}$ & $\begin{array}{l}k T \text {-dimensional vector of prices of the product at the demand markets with } \\
\text { component } k t: \rho_{3 k t}\end{array}$ \\
\hline$\rho_{3 t}$ & $\begin{array}{l}k \text {-dimensional vector of prices of the product at the demand markets } \\
\text { at time period } t \text { with component } k: \rho_{3 k t}\end{array}$ \\
\hline
\end{tabular}


Table 2: Demand and Cost Functions in the Multiperiod Supply Chain Network Equilibrium Model

\begin{tabular}{|l|l|}
\hline Notation & Definition \\
\hline$d_{k t}\left(\rho_{3 t}\right)$ & $\begin{array}{l}\text { demand function at demand market } k \text { at time period } t \\
f_{i t}(q)\end{array}$ \\
$c_{i j t}\left(q_{i j t}\right)$ & $\begin{array}{l}\text { production cost of manufacturer } i \text { at period } t \text { with marginal production cost } \\
\text { transaction cost between manufacturer } i \text { and retailer } j \text { at period } t \\
\text { with marginal transaction cost: } \frac{\partial c_{i j t}\left(q_{i j t}\right)}{\partial q_{i j t}}\end{array}$ \\
$c_{j t}\left(h_{t}\right)$ & $\begin{array}{l}\text { handling cost of retailer } j \text { at time period } t \text { with marginal handling cost with } \\
\text { respect to } h_{j t}: \frac{\partial c_{j t}}{\partial h_{j t}}\end{array}$ \\
$v_{i t}\left(u_{i t}\right)$ & $\begin{array}{l}\text { inventory cost of manufacturer } i \text { at time period } t \text { with marginal inventory cost } \\
\text { with respect to } u_{i t}: \frac{\partial c v_{i t}}{\partial u_{i t}}\end{array}$ \\
$v_{j t}\left(u_{j t}\right)$ & $\begin{array}{l}\text { inventory cost of retailer } j \text { at time period } t \text { with marginal inventory cost with } \\
\text { respect to } u_{j t}: \frac{\partial c v_{j t}}{\partial u_{j t}}\end{array}$ \\
$\hat{c}_{j k t}\left(Q_{t}^{2}\right)$ & unit transaction cost between retailer $j$ and demand market $k$ at time period $t$ \\
\hline
\end{tabular}

state the equilibrium conditions for the multiperiod supply chain network and provide the finite-dimensional variational inequality governing the equilibrium.

\subsection{The Behavior of the Manufacturers and their Optimality Conditions}

Let $\rho_{1 i j t}^{*}$ denote the price charged for the product by manufacturer $i$ in transacting with retailer $j$ in period $t$. The price $\rho_{1 i j t}^{*}$ is an endogenous variable and will be determined once the entire multiperiod supply chain network equilibrium model is solved. We assume that the quantity produced by manufacturer $i$ must satisfy the following conservation of flow equations:

$$
\begin{gathered}
\sum_{j=1}^{n} q_{i j 1}+u_{i 1}=q_{i 1} \\
u_{i t}+\sum_{j=1}^{n} q_{i j t}=q_{i t}+u_{i(t-1)}, \quad t=2, \ldots, T-1, \\
\sum_{j=1}^{n} q_{i j T}=q_{i T}+u_{i(T-1)} .
\end{gathered}
$$

Constraints (1), (2), and (3) state that at each period, the amount of product available for 
distribution at that time period and inventorying to the next period, is equal to the amount produced in that period plus the amount inventoried from the preceding period, with zero inventories assumed before the first time period and after the final time period $T$.

The objective of the manufacturers is to maximize the total profit over the planning horizon $T$. The decision variables for manufacturer $i$ are: the production levels at each period, $q_{t} ; t=1, \ldots, T$, the distribution quantities in each period, $q_{i j t} ; j=1, \ldots, n ; t=1, \ldots, T$, and the inventory level at the end of each period, $u_{i t} ; t=1, \ldots, T-1$. Thus, manufacturer $i$ is faced with an optimization problem which can be expressed as follows:

$$
\text { Maximize } \sum_{t=1}^{T} \sum_{j=1}^{n} \rho_{1 i j t}^{*} q_{i j t}-\sum_{t=1}^{T} f_{i t}(q)-\sum_{t=1}^{T} c v_{i t}\left(u_{i t}\right)-\sum_{t=1}^{T} \sum_{j=1}^{n} c_{i j t}\left(q_{i j t}\right)
$$

subject to (1), (2), and (3), and

$$
\begin{gathered}
q_{i j t} \geq 0, \quad j=1, \ldots, n ; \quad t=1, \ldots, T, \\
q_{i t} \geq 0, \quad t=1, \ldots, T \\
u_{i t} \geq 0, \quad t=1, \ldots, T-1 .
\end{gathered}
$$

The first term in (4) represents the revenue and the subsequent three terms the production costs, inventory costs, and the transaction costs, respectively, for manufacturer $i$. Note that we allow the specifications of all the cost functions to be time-dependent.

We assume that the production cost functions $f_{i t} ; i=1, \ldots, m ; t=1, \ldots, T$ are continuously differentiable and convex as are the transaction cost functions, $c_{i j t} ; i=1, \ldots, m$; $j=1, \ldots, n ; t=1, \ldots, T$, and the inventory cost functions $c v_{i t} ; i=1, \ldots, m ; t=1, \ldots, T$.

We assume that the manufacturers compete in a noncooperative manner in the sense of Nash (1950, 1951) (see also, e.g., Nagurney et al. (2002) and Nagurney et al. (2005)). The optimality conditions for all manufacturers $i ; i=1, \ldots, m$, simultaneously, can then be expressed as the following variational inequality (cf. Nagurney et al. (2002), Bazaraa et al. (1993), Gabay and Moulin (1980); see also Dafermos and Nagurney (1987) and Nagurney (1999)): determine $\left(q^{*}, u^{1 *}, Q^{1 *}\right) \in \mathcal{K}^{1}$ satisfying:

$$
\sum_{t=1}^{T} \sum_{\tau=1}^{T} \sum_{i=1}^{m} \frac{\partial f_{i t}\left(q^{*}\right)}{\partial q_{i \tau}} \times\left[q_{i \tau}-q_{i \tau}^{*}\right]+\sum_{t=1}^{T} \sum_{i=1}^{m} \sum_{j=1}^{n}\left[\frac{\partial c_{i j t}\left(q_{i j t}^{*}\right)}{\partial q_{i j t}}-\rho_{1 i j t}^{*}\right] \times\left[q_{i j t}-q_{i j t}^{*}\right]
$$




$$
+\sum_{t=1}^{T} \sum_{i=1}^{m} \frac{\partial c v_{i t}\left(u_{i t}^{*}\right)}{\partial u_{i t}} \times\left[u_{i t}-u_{i t}^{*}\right] \geq 0, \quad \forall\left(q, u^{1}, Q^{1}\right) \in \mathcal{K}^{1},
$$

where $\mathcal{K}^{1} \equiv\left\{\left(q, u^{1}, Q^{1}\right) \mid\left(q, u^{1}, Q^{1}\right) \in R_{+}^{T m(2+n)}\right.$ and (1), (2), and (3) hold $\}$.

\subsection{The Behavior of the Retailers and their Optimality Conditions}

The retailers, in turn, purchase the product from the manufacturers and transact with the consumers at the demand markets. Thus, a retailer is involved in transactions both with the manufacturers as well as with customers at the demand markets.

Let $\rho_{2 j t}^{*}$ denote the price charged by retailer $j$ for the product at time period $t$. This price will be determined endogenously after the complete model is solved. We assume that the objective of a retailer is to maximize his total profit over the planning horizon $T$. The decision variables of retailer $j$ include: the procurement in each period, $q_{i j t} ; i=1, \ldots, m ; t=1, \ldots, T$, the sales made at each period, $q_{j k t} ; k=1, \ldots, o ; t=1, \ldots, T$, and the inventory level at the end of each period, $u_{j t} ; t=1, \ldots, T-1$. Hence, the optimization problem faced by retailer $j$ is given by:

$$
\text { Maximize } \sum_{t=1}^{T} \sum_{k=1}^{o} \rho_{2 j t}^{*} q_{j k t}-\sum_{t=1}^{T} c_{j t}\left(h_{t}\right)-\sum_{t=1}^{T} c v_{j t}\left(u_{j t}\right)-\sum_{t=1}^{T} \sum_{i=1}^{m} \rho_{1 i j t}^{*} q_{i j t}
$$

subject to:

$$
\begin{gathered}
h_{j t}=\sum_{i=1}^{m} q_{i j t}, \quad t=1, \ldots, T, \\
\sum_{k=1}^{o} q_{j k 1}+u_{j 1}=\sum_{i=1}^{m} q_{i j 1}, \\
\sum_{k=1}^{o} q_{j k t}+u_{j t}=\sum_{i=1}^{m} q_{i j t}+u_{j(t-1)}, \quad t=2, \ldots, T-1, \\
\sum_{k=1}^{o} q_{j k T}=\sum_{i=1}^{m} q_{i j T}+u_{j(T-1)},
\end{gathered}
$$

and the nonnegativity constraints:

$$
\begin{gathered}
q_{i j t} \geq 0, \quad i=1, \ldots, m ; t=1, \ldots, T \\
q_{j k t} \geq 0, \quad k=1, \ldots, m ; t=1, \ldots, T \\
u_{j t} \geq 0, \quad t=1, \ldots, T
\end{gathered}
$$


The first term in the objective function (6) represents the revenue of retailer $j$, whereas the second, third, and the fourth terms represent, respectively, the handling cost, the inventory cost and the payout to the manufacturers. Constraints (8), (9), and (10) state that the amount available of the product for distribution to the demand markets in a time period is equal to the amount obtained in that period from the manufacturers plus the amount inventoried from the preceding period minus the amount inventoried for the next time period. Constraint (7) is a notational constraint that will be useful in our transportation network equivalence.

We assume that the handling cost functions for each retailer $c_{j t} ; j=1, \ldots, n ; t=1, \ldots T$, are continuously differentiable and convex as are the inventory cost functions $c v_{j t} ; j=$ $1, \ldots, n ; t=1, \ldots, T$.

We assume that the retailers also compete in a noncooperative manner. Then the optimality conditions for all the retailers simultaneously can be expressed as the variational inequality: determine $\left(Q^{1 *}, h^{*}, u^{2 *}, Q^{2 *}\right) \in \mathcal{K}^{2}$ satisfying:

$$
\begin{gathered}
\sum_{t=1}^{T} \sum_{j=1}^{n} \frac{\partial c_{j t}\left(h_{t}^{*}\right)}{\partial h_{j t}} \times\left[h_{j t}-h_{j t}^{*}\right]+\sum_{t=1}^{T} \sum_{i=1}^{m} \sum_{j=1}^{n} \rho_{1 i j t}^{*} \times\left[q_{i j t}-q_{i j t}^{*}\right]-\sum_{t=1}^{T} \sum_{j=1}^{n} \sum_{k=1}^{o} \rho_{2 j t}^{*} \times\left[q_{j k t}-q_{j k t}^{*}\right] \\
+\sum_{t=1}^{T} \sum_{j=1}^{n} \frac{\partial c v_{j t}\left(u_{j t}^{*}\right)}{\partial u_{j t}} \times\left[u_{j t}-u_{j t}^{*}\right] \geq 0, \quad \forall\left(Q^{1}, h, u^{2}, Q^{2}\right) \in \mathcal{K}^{2}
\end{gathered}
$$

where $\mathcal{K}^{2} \equiv\left\{\left(Q^{1}, h, u^{2}, Q^{1}\right) \mid\left(Q^{1}, h, u^{2}, Q^{1}\right) \in R_{+}^{T n(m+o+2)}\right.$ and (7), (8), (9), and (10) hold $\}$.

\section{The Consumers at the Demand Markets and the Equilibrium Conditions}

We now describe the behavior of the consumers located at the demand markets. The consumers take into account in making their consumption decisions not only the prices charged for the product by the retailers, $\rho_{2 j t}^{*} ; j=1, \ldots, n ; t=1, \ldots, T$, but also on the unit transaction costs to obtain the product. The equilibrium conditions for consumers at demand market $k$, (cf. Samuelson (1952) and Takayama and Judge (1971)) take the form: for all retailers $j ; j=1, \ldots, n$ and time periods $t ; t=1, \ldots, T$ :

$$
\rho_{2 j t}^{*}+\hat{c}_{j k t}\left(Q_{t}^{2^{*}}\right)\left\{\begin{array}{lll}
=\rho_{3 k t}^{*}, & \text { if } & q_{j k t}^{*}>0, \\
\geq \rho_{3 k t}^{*}, & \text { if } & q_{j k t}^{*}=0,
\end{array}\right.
$$


and

$$
d_{k t}\left(\rho_{3 t}^{*}\right)\left\{\begin{array}{lll}
=\sum_{j=1}^{n} q_{j k t}^{*}, & \text { if } & \rho_{3 k t}^{*}>0 \\
\leq \sum_{j=1}^{n} q_{j k t}^{*}, & \text { if } & \rho_{3 k t}^{*}=0
\end{array}\right.
$$

Note that we allow the specification of the elastic demand function $d_{k t}\left(\rho_{3 t}^{*}\right)$ to be timedependent.

Conditions (12) state that, in equilibrium, at each time period, if the consumers at demand market $k$ purchase the product from retailer $j$, then the price charged by the retailer for the product at that time period plus the unit transaction cost is equal to the price that the consumers are willing to pay for the product at that time period. If the price plus the unit transaction cost is higher than the price the consumers are willing to pay at the demand market then there will be no transaction between the retailer and demand market pair at that time period. Conditions (13) state, in turn, that if the equilibrium price the consumers are willing to pay for the product at the demand market at the time period is positive, then the quantities purchased of the product from the retailers at that time period will be precisely equal to the demand for that product at the demand market at that time period. If the equilibrium price at the demand market is zero at the time period then the shipments to that demand market may exceed the actually demand at the time period.

For notational convenience (see also Table 1), we let:

$$
d_{k t}=\sum_{j=1}^{n} q_{j k t} \quad k=1, \ldots, o ; \quad t=1, \ldots, T .
$$

In equilibrium, condition (12) and (13) must hold simultaneously for all demand markets $k ; k=1, \ldots, o$ at all the time periods. We can also express these equilibrium conditions using the following variational inequality: determine $\left(Q^{2 *}, d^{*}, \rho_{3}^{*}\right) \in \mathcal{K}^{3}$, such that

$$
\begin{aligned}
& \sum_{t=1}^{T} \sum_{j=1}^{n} \sum_{k=1}^{o} \hat{c}_{j k t}\left(Q_{t}^{2 *}\right) \times\left[q_{j k t}-q_{j k t}^{*}\right]+\sum_{t=1}^{T} \sum_{k=1}^{o} \rho_{3 k t}^{*} \times\left[d_{k t}-d_{k t}^{*}\right] \\
+ & \sum_{t=1}^{T} \sum_{k=1}^{o}\left[d_{k t}^{*}-d_{k t}\left(\rho_{3 t}^{*}\right)\right] \times\left[\rho_{3 k t}-\rho_{3 k t}^{*}\right] \geq 0, \quad \forall\left(Q^{2}, d, \rho_{3}\right) \in \mathcal{K}^{3},
\end{aligned}
$$

where $\mathcal{K}^{3} \equiv\left\{\left(Q^{2}, d, \rho_{3}\right) \mid\left(Q^{2}, d, \rho_{3}\right) \in R_{+}^{T(n o+2 o)}\right.$ and (14) holds $\}$. 


\section{The Equilibrium Conditions of the Multiperiod Supply Chain Network}

In equilibrium, the optimality conditions for all manufacturers, the optimality conditions for all retailers, and the equilibrium conditions for all the demand markets must hold simultaneously so that no decision-maker can be better off by altering his decisions. Also, the shipments that the manufacturers ship to the retailers must be equal to the shipments that the retailers accept from the manufacturers. Similarly, the quantities of the product obtained by the consumers at the demand markets must coincide with the amounts sold by the retailers.

\section{Definition 1: Multiperiod Supply Chain Network Equilibrium}

The equilibrium state of the multiperiod supply chain network is one where the sum of (5), (11), and (15) is satisfied, so that no decision-maker has any incentive to alter his decisions.

We now state Theorem 1.

\section{Theorem 1: Variational Inequality Formulation}

The equilibrium conditions governing the multiperiod supply chain network model are equivalent to the solution of the variational inequality problem given by: determine

$$
\left(q^{*}, h^{*}, u^{1 *}, Q^{1^{*}}, u^{2 *}, Q^{2^{*}}, d^{*}, \rho_{3}^{*}\right) \in \mathcal{K}^{4}
$$

satisfying:

$$
\begin{gathered}
\sum_{t=1}^{T} \sum_{\tau=1}^{T} \sum_{i=1}^{m} \frac{\partial f_{i t}\left(q^{*}\right)}{\partial q_{i \tau}} \times\left[q_{i \tau}-q_{i \tau}^{*}\right]+\sum_{t=1}^{T} \sum_{i=1}^{m} \sum_{j=1}^{n} \frac{\partial c_{i j t}\left(q_{i j t}^{*}\right)}{\partial q_{i j t}} \times\left[q_{i j t}-q_{i j t}^{*}\right]+\sum_{t=1}^{T} \sum_{j=1}^{n} \frac{\partial c_{j t}\left(h_{t}^{*}\right)}{\partial h_{j t}} \times\left[h_{j t}-h_{j t}^{*}\right] \\
+\sum_{t=1}^{T} \sum_{i=1}^{m} \frac{\partial c v_{i t}\left(u_{i t}^{*}\right)}{\partial u_{i t}} \times\left[u_{i t}-u_{i t}^{*}\right]+\sum_{t=1}^{T} \sum_{j=1}^{n} \frac{\partial c v_{j t}\left(u_{j t}^{*}\right)}{\partial u_{j t}} \times\left[u_{j t}-u_{j t}^{*}\right] \\
+\sum_{t=1}^{T} \sum_{j=1}^{n} \sum_{k=1}^{o} \hat{c}_{j k t}\left(Q_{t}^{2 *}\right) \times\left[q_{j k t}-q_{j k t}^{*}\right]+\sum_{t=1}^{T} \sum_{k=1}^{o} \rho_{3 k t}^{*} \times\left[d_{k t}-d_{k t}^{*}\right] \\
+\sum_{t=1}^{T} \sum_{k=1}^{o}\left[d_{k t}^{*}-d_{k t}\left(\rho_{3 t}^{*}\right)\right] \times\left[\rho_{3 k t}-\rho_{3 k t}^{*}\right] \geq 0, \quad \forall\left(q, h, u^{1}, Q^{1}, u^{2}, Q^{2}, d, \rho_{3}\right) \in \mathcal{K}^{4},
\end{gathered}
$$

where $\mathcal{K}^{4} \equiv\left\{\left(q, h, u^{1}, Q^{1}, u^{2}, Q^{2}, d, \rho_{3}\right) \mid\right.$

$\left(q, h, u^{1}, Q^{1}, u^{2}, Q^{2}, d, \rho_{3}\right) \in R_{+}^{T(2 m+m n+2 n+n o+2 o)}$ and (1), (2), (3), (7), (8), (9), (10), and (14) hold $\}$. 
Proof: Similar to proof of equivalences in Nagurney (2006b).

\section{The Transportation Network Equilibrium Model with Elastic Demands}

In this section, we recall a transportation network equilibrium model with elastic demands. We assume that the demand functions associated with the origin/destination (O/D) pairs are given, and we provide the single-modal version of the model of Dafermos and Nagurney (1984b).

Consider a network $G$ with the set of directed links $L$ consisting of $K$ elements, the set of paths $P$ consisting of $n_{P}$ elements. Let $W$ denote the set of O/D pairs with $n_{W}$ elements. Let $P_{w}$ denote the set of paths connecting O/D pair $w$. Links are denoted by $a, b$, etc; paths by $p, q$, etc., and $\mathrm{O} / \mathrm{D}$ pairs by $w, \omega$, etc.

We denote the flow on path $p$ by $x_{p}$ and the flow on link $a$ by $f_{a}$. We group the path flows into the vector $x$ and the link flows into the vector $f$. We also denote the user travel cost on path $p$ by $C_{p}$ and the user travel cost on link $a$ by $c_{a}$. The travel demand associated with traveling between O/D pair $w$ is denoted by $d_{w}$ and the travel disutility by $\lambda_{w}$.

We assume that the following conservation of flow equations hold:

$$
f_{a}=\sum_{p \in P} x_{p} \delta_{a p}, \quad \forall a \in L,
$$

where $\delta_{a p}=1$ if link $a$ is contained in path $p$, and $\delta_{a p}=0$, otherwise. Expression (17) means that the flow on a link is equal to the sum of the flows on paths that contain that link.

The user travel cost on a path is equal to the sum of user travel costs on links that comprise the path:

$$
C_{p}=\sum_{a \in L} c_{a} \delta_{a p}, \quad \forall p \in P .
$$

Here we consider the general situation where the cost on a link may depend upon the entire vector of link flows, so that

$$
c_{a}=c_{a}(f), \quad \forall a \in L .
$$

We assume that the travel demand functions are given as follows:

$$
d_{w}=d_{w}(\lambda), \quad \forall w \in W,
$$


where $\lambda$ is the vector of travel disutilities with the travel disutility associated with O/D pair being denoted by $\lambda_{w}$.

As given in Dafermos and Nagurney (1984b); see also Aashtiani and Magnanti (1981), Fisk and Boyce (1982), Nagurney and Zhang (1996), and Nagurney (1999), a travel path flow and disutility pattern $\left(x^{*}, \lambda^{*}\right) \in R_{+}^{n_{P}+n_{W}}$ is said to be an equilibrium, if, once established, no user can be better off by unilaterally altering his travel decisions. The state is characterized by the following equilibrium conditions which must hold for every $\mathrm{O} / \mathrm{D}$ pair $w \in W$ and every path $p \in P_{w}$ :

$$
C_{p}\left(x^{*}\right)-\lambda_{w}^{*}\left\{\begin{array}{lll}
=0, & \text { if } & x_{p}^{*}>0 \\
\geq 0, & \text { if } \quad x_{p}^{*}=0
\end{array}\right.
$$

and

$$
\sum_{p \in P_{w}} x_{p}^{*}\left\{\begin{array}{lll}
=d_{w}\left(\lambda^{*}\right), & \text { if } & \lambda_{w}^{*}>0, \\
\geq d_{w}\left(\lambda^{*}\right), & \text { if } & \lambda_{w}^{*}=0 .
\end{array}\right.
$$

Condition (21) states that all utilized paths connecting an O/D pair have equal and minimal travel costs which are equal to the travel disutility associated with traveling between that O/D pair. Condition (22) states that the market clears for each O/D pair under a positive price or travel disutility. As described in Dafermos and Nagurney (1984b) the transportation network equilibrium conditions (21) and (22) can be expressed as the variational inequality: determine $\left(x^{*}, \lambda^{*}\right) \in R_{+}^{n_{P}+n_{W}}$ such that

$\sum_{w \in W} \sum_{p \in P_{w}}\left[C_{p}\left(x^{*}\right)-\lambda_{w}^{*}\right] \times\left[x_{p}-x_{p}^{*}\right]+\sum_{w \in W} \sum_{p \in P_{w}}\left[x_{p}^{*}-d_{w}\left(\lambda^{*}\right)\right] \times\left[\lambda_{w}-\lambda_{w}^{*}\right] \geq 0, \forall(x, \lambda) \in R_{+}^{n_{P}+n_{W}}$.

Note that variational inequality (23) is in path flows. Now we also provide the equivalent variational inequality but in link flows, also due to Dafermos and Nagurney (1984b). For additional background, see the book by Nagurney (1999).

\section{Theorem 2}

A travel link flow pattern and associated travel demand and disutility pattern is a transportation network equilibrium if and only if it satisfies the variational inequality problem: determine $\left(f^{*}, d^{*}, \lambda^{*}\right) \in \mathcal{K}^{5}$ satisfying

$$
\sum_{a \in L} c_{a}\left(f^{*}\right) \times\left(f_{a}-f_{a}^{*}\right)-\sum_{w \in W} \lambda_{w}^{*} \times\left(d_{w}-d_{w}^{*}\right)+\sum_{w \in W}\left[d_{w}^{*}-d_{w}\left(\lambda^{*}\right)\right] \times\left[\lambda_{w}-\lambda_{w}^{*}\right] \geq 0, \quad \forall(f, d, \lambda) \in \mathcal{K}^{5},
$$




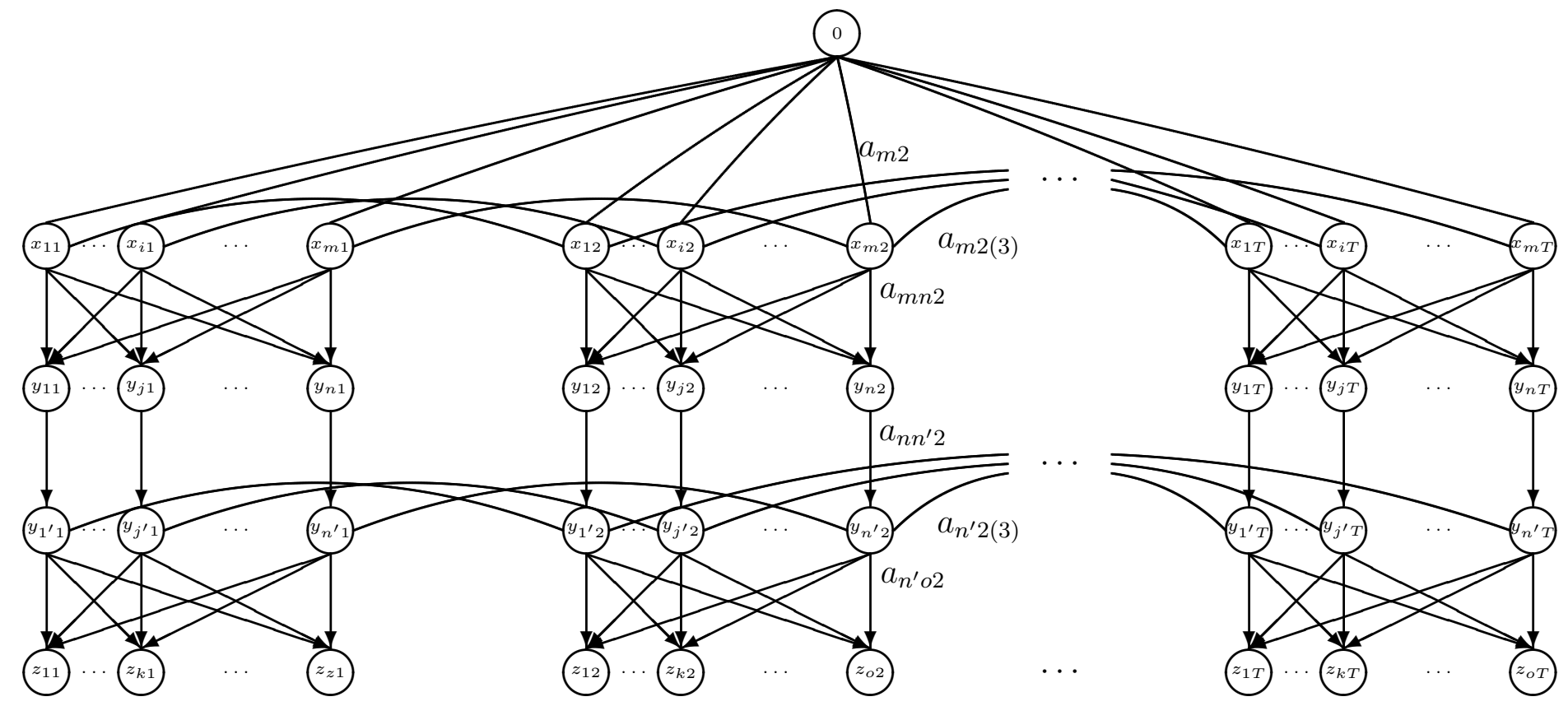

Figure 2: The $\mathcal{G}_{S}$ Supernetwork Representation of the Multiperiod Supply Chain Network

where $\mathcal{K}^{5} \equiv\left\{(f, d, \lambda) \in R_{+}^{K+2 n_{W}} \mid\right.$ there exists an $x$ satisfying $(16)$ and $\left.d_{w}=\sum_{p \in P_{w}} x_{p}, \forall w\right\}$.

In the next section, we will reformulate the multiperiod supply chain network model in Section 2 as a properly configured transportation network (through a supernetwork construction) by showing that the link flow variational inequality (24) for the constructed transportation network coincides with variational inequality (16).

\section{Transportation Network Equilibrium Reformulation of Multiperiod Supply Chain Network Equilibrium}

In this section, we establish the supernetwork equivalence of the multiperiod supply chain network equilibrium with a properly configured transportation network equilibrium model with elastic demand as discussed in Section 3.

We consider a multiperiod supply chain network as discussed in Section 2 which consists of $T$ periods; $m$ manufacturers: $i=1, \ldots, m$; $n$ retailers: $j=1, \ldots, n$, and $o$ demand markets: $k=1, \ldots, o$. The supernetwork $\mathcal{G}_{\mathcal{S}}$ of the isomorphic transportation network equilibrium model is depicted in Figure 2 and is constructed as follows. The supernetwork $\mathcal{G}_{\mathcal{S}}$ consists of the single origin node 0 at the top tier, and $o \times T$ destination nodes at the bottom tier denoted, respectively, by $z_{k t_{3}} ; k=1, \ldots, o ; t_{3}=1, \ldots, T$. Thus, there are $o T \mathrm{O} / \mathrm{D}$ pairs in 
$\mathcal{G}_{\mathcal{S}}$ denoted, respectively, by $w_{11}=\left(0, z_{11}\right), \ldots, w_{k t_{3}}=\left(0, z_{k t_{3}}\right), \ldots, w_{o T}=\left(0, z_{o T}\right)$. Node 0 is connected to each second-tiered node $x_{i t_{1}}$, where $i=1, \ldots, m$ and $t_{1}=1, \ldots, T$. Each second-tiered node $x_{i t_{1}}$, in turn, is connected to each third-tiered node $y_{j t_{2}}$ with $t_{2}=t_{1}$, and $j=1, \ldots, n$. Each node $x_{i t_{1}}$ is also connected to $x_{i\left(t_{1}+1\right)}$ with the same subscript $i$. Each node $y_{j t_{2}}$, in turn, is connected with a corresponding node $y_{j^{\prime} t_{2}}$ in the fourth tier by a single link. Each node $y_{j^{\prime} t_{2}}$ is linked to node $y_{j^{\prime} t_{2}+1}$ with the same $j^{\prime}$ in the same tier by a single link. Finally, from each fourth-tiered node $y_{j^{\prime} t_{2}}$ there are $o$ links emanating to the bottom-tiered nodes $z_{k t_{3}}$ with $t_{3}=t_{2}$. There are, hence, $1+T(m+2 n+o)$ nodes, $K=T(m+m n+n+n o)+(T-1)(m+n)$ links, $n_{W}=o T \mathrm{O} / \mathrm{D}$ pairs, and $n_{P}=\frac{(T+1) T}{2} m n o$ paths in the supernetwork in Figure 2.

We now define the links in the supernetwork in Figure 2 and the associated flows. Let $a_{i t_{1}}$ denote the link from node 0 to node $x_{i t_{1}}$ with associated link flow $f_{a_{i t_{1}}}$, for $i=1, \ldots, m ; t_{1}=$ $1, \ldots, T$. Let $a_{i t_{1}\left(t_{1}+1\right)}$ denote the link from node $x_{i t_{1}}$ to node $x_{i\left(t_{1}+1\right)}$ with associated link flow $f_{a_{i t_{1}\left(t_{1}+1\right)}}$ for $i=1, \ldots, m$, and $t_{1}=1, \ldots, T-1$. Let $a_{i j t_{2}}$ denote the link from node $x_{i t_{1}}$ to node $y_{j t_{2}}$ with associated link flow $f_{a_{i j t_{2}}}$ for $i=1, \ldots, m ; j=1, \ldots, n$, and $t_{1}=t_{2}=1, \ldots, T$. Also, let $a_{j j^{\prime} t_{2}}$ denote the link connecting node $y_{j t_{2}}$ with node $y_{j^{\prime} t_{2}}$ with associated link flow $f_{a_{j j^{\prime} t_{2}}}$ for $j ; j=1, \ldots, n, j^{\prime} ; j^{\prime}=1, \ldots, n$, and $t_{2}=1, \ldots, T$. Let $a_{j^{\prime} t_{2}\left(t_{2}+1\right)}$ denote the link from node $y_{j^{\prime} t_{2}}$ to node $y_{j^{\prime}\left(t_{2}+1\right)}$ with associated link flow $f_{a_{j^{\prime} t_{2}\left(t_{2}+1\right)}}$ for $j^{\prime}=1, \ldots, n$ and $t_{2}=1, \ldots, T-1$. Finally, let $a_{j^{\prime} k t_{3}}$ denote the link joining node $y_{j^{\prime} t_{2}}$ with node $z_{k t_{3}}$ for $j^{\prime}=1^{\prime}, \ldots, n^{\prime} ; k=1, \ldots, o$, and $t_{2}=t_{3}=1, \ldots, T$, and with associated link flow $f_{a_{j^{\prime} k t_{3}}}$.

We group the $\left\{f_{a_{i t_{1}}}\right\}$ into the vector $f^{1}$; the $\left\{f_{a_{i j t_{2}}}\right\}$ into the vector $f^{2}$; the $\left\{f_{a_{i t_{1}\left(t_{1}+1\right)}}\right\}$ into the vector $f^{3}$; the $\left\{f_{a_{j^{\prime} t_{2}}}\right\}$ into the vector $f^{4}$; the $\left\{f_{a_{j^{\prime} t_{2}\left(t_{2}+1\right)}}\right\}$ into the vector $f^{5}$, and the $\left\{f_{a_{j^{\prime} k t_{3}}}\right\}$ into the vector $f^{6}$.

Hence, the paths in $\mathcal{G}_{\mathcal{S}}, p_{i t_{1} j t_{2} j^{\prime} k t_{3}}$, can be classified into four groups based on the types of links that they are comprised of. The first group of paths consists of four links: $a_{i t_{1}}, a_{i j t_{2}}$, $a_{j j^{\prime} t_{2}}$, and $a_{j^{\prime} k t_{3}}$ with $t_{1}=t_{2}=t_{3}$. In this group of paths there are no inventory links. The second group of paths consists of five types of links: $a_{i t_{1}}, a_{i t_{1}\left(t_{1}+1\right)}, a_{i j t_{2}}, a_{j j^{\prime} t_{2}}$, and $a_{j^{\prime} k t_{3}}$ with $t_{1}<t_{2}=t_{3}$. In this group of paths there are inventory links at the manufacturers. The third group of paths also consist of five types of links: $a_{i t_{1}}, a_{i j t_{2}}, a_{j j^{\prime} t_{2}}, a_{j^{\prime} t_{2}\left(t_{2}+1\right)}$, and $a_{j^{\prime} k t_{3}}$ with $t_{1}=t_{2}<t_{3}$. In this group there are inventory links at the retailers. Finally, the fourth group of paths consists of six types of links: $a_{i t_{1}}, a_{i t_{1}\left(t_{1}+1\right)}, a_{i j t_{2}}, a_{j j^{\prime} t_{2}}, a_{j^{\prime} t_{2}\left(t_{2}+1\right)}$, and $a_{j^{\prime} k t_{3}}$ with $t_{1}<t_{2}<t_{3}$. In this group there are inventory links at the manufacturers and at the 
retailers.

We denote the path flow associated with path $p_{i t_{1} j t_{2} j^{\prime} k t_{3}}$ by $x_{p_{i t_{1} j t_{2} j^{\prime} k t_{3}}}$. Also, we let $d_{w_{k} t_{3}}\left(\lambda_{w_{k} t_{3}}\right)$ denote the known elastic demand function associated with O/D pair $w_{k}$ at time period $t_{3}$ and we let $\lambda_{w_{k} t_{3}}$ denote the travel disutility associated with $\mathrm{O} / \mathrm{D}$ pair $w_{k}$ at time period $t_{3}$.

We assume that the link flows satisfy the conservation of flow equations (17), that is:

$$
\begin{aligned}
& f_{a_{i t_{1}}}=\sum_{j=1}^{n} \sum_{j^{\prime}=1^{\prime}}^{n^{\prime}} \sum_{k=1}^{o} \sum_{t_{2}=t_{1}}^{T} \sum_{t_{3}=t_{2}}^{T} x_{p_{i t_{1} j t_{2} j^{\prime} k t_{3}}}, \quad i=1, \ldots, m ; t_{1}=1, \ldots, T, \\
& f_{a_{i j t_{2}}}=\sum_{j^{\prime}=1^{\prime}}^{n^{\prime}} \sum_{k=1}^{o} \sum_{t_{1}=1}^{t_{2}} \sum_{t_{3}=t_{2}}^{T} x_{p_{i t_{1} j t_{2} j^{\prime} k t_{3}}}, \quad i=1, \ldots, m ; j=1, \ldots, n ; t_{2}=1, \ldots, T, \\
& f_{a_{j j^{\prime} t_{2}}}=\sum_{i=1}^{m} \sum_{k=1}^{o} \sum_{t_{1}=1}^{t_{2}} \sum_{t_{3}=t_{2}}^{T} x_{p_{i t_{1} j t_{2} j^{\prime} k t_{3}}}, \quad j=1, \ldots, n ; j^{\prime}=1, \ldots, n ; t_{2}=1, \ldots, T \text {, } \\
& f_{a_{j^{\prime} k t_{3}}}=\sum_{i=1}^{m} \sum_{j=1}^{n} \sum_{t_{1}=1}^{t_{3}} \sum_{t_{2}=t_{1}}^{t_{3}} x_{p_{i t_{1} j t_{2} j^{\prime} k t_{3}}}, \quad j^{\prime}=1, \ldots, n ; k=1, \ldots, o ; t_{3}=1, \ldots, T, \\
& f_{a_{i t_{1}\left(t_{1}+1\right)}}=\sum_{j=1}^{n} \sum_{j^{\prime}=1^{\prime}}^{n^{\prime}} \sum_{k=1}^{o} \sum_{t_{2}=t_{1}+1}^{T} \sum_{t_{3}=t_{2}}^{T} x_{p_{i t_{1} j t_{2} j^{\prime} k t_{3}}}, \quad i=1, \ldots, m ; t_{1}=1, \ldots, T-1, \\
& f_{a_{j^{\prime} t_{2}\left(t_{2}+1\right)}}=\sum_{i=1}^{m} \sum_{j=1}^{n} \sum_{t_{1}=1}^{t_{2}} \sum_{t_{3}=t_{2}+1}^{T} x_{p_{i t_{1} j t_{2} j^{\prime} k t_{3}}}, j^{\prime}=1, \ldots, n ; t_{2}=1, \ldots, T-1 .
\end{aligned}
$$

Also, we have that

$$
d_{w_{k} t_{3}}=\sum_{i=1}^{m} \sum_{j=1}^{n} \sum_{j^{\prime}=1}^{n^{\prime}} \sum_{t_{1}=1}^{t_{3}} \sum_{t_{2}=t_{1}}^{t_{3}} x_{p_{i t_{1} j t_{2} j^{\prime} k t_{3}}}, \quad k=1, \ldots, o ; t_{3}=1, \ldots, T .
$$

A path flow pattern induces a feasible link flow pattern if all path flows are nonnegative and (25)-(31) are satisfied.

Given a feasible product shipment/transaction pattern for the supply chain model with elastic demands, $\left(q, u^{1}, Q^{1}, h, u^{2}, Q^{2}\right) \in \mathcal{K}^{4}$, we may construct a feasible link flow pattern on the network $\mathcal{G}_{\mathcal{S}}$ as follows: the link flows are defined as:

$$
q_{i t} \equiv f_{a_{i t_{1}}}, \quad i=1, \ldots, m ; t_{1}=t=1, \ldots, T
$$




$$
\begin{gathered}
u_{i t} \equiv f_{a_{i t_{1}\left(t_{1}+1\right)}}, \quad i=1, \ldots, m ; t_{1}=t=1, \ldots, T-1, \\
q_{i j t} \equiv f_{a_{i j t_{2}}}, \quad i=1, \ldots, m ; j=1, \ldots, n ; t_{2}=t=1, \ldots, T, \\
h_{j t} \equiv f_{a_{j^{\prime} t_{2}}}, \quad j=1, \ldots, n ; j^{\prime}=1, \ldots, n^{\prime} ; t_{2}=t=1, \ldots, T, \\
u_{j t} \equiv f_{a_{j^{\prime} t_{2}\left(t_{2}+1\right)}}, \quad j=1, \ldots, n ; j^{\prime}=1, \ldots, n^{\prime} ; t_{2}=t=1, \ldots, T-1, \\
q_{j k t}=f_{a_{j^{\prime} k t_{3}}}, \quad j=1, \ldots, n ; j^{\prime}=1^{\prime}, \ldots, n^{\prime} ; k=1, \ldots, o ; t_{3}=t=1, \ldots, T .
\end{gathered}
$$

Note that if $\left(q, u^{1}, Q^{1}, h, u^{2}, Q^{2}\right)$ is feasible then the link flow pattern constructed according to $(32)-(37)$ is also feasible and the corresponding path flow pattern that induces such a link flow pattern is, hence, also feasible.

We now assign travel costs on the links of the network $\mathcal{G}_{\mathcal{S}}$ as follows: with each link $a_{i}$ we assign a travel cost $c_{a_{i t_{1}}}$ defined by

$$
c_{a_{i t_{1}}} \equiv \sum_{\tau=1}^{T} \frac{\partial f_{i \tau}(q)}{\partial q_{i t}}, \quad i=1, \ldots, m ; t_{1}=t=1, \ldots, T
$$

with each link $a_{i t(t+1)}$ we assign a travel cost $c_{a_{i t_{1}\left(t_{1}+1\right)}}$ defined by:

$$
c_{a_{i t_{1}\left(t_{1}+1\right)}} \equiv \frac{\partial c v_{i t}\left(u_{t}^{1}\right)}{\partial u_{i t}}, \quad i=1, \ldots, m ; j=1, \ldots, n ; t_{1}=t=1, \ldots, T-1 ;
$$

with each link $a_{i j t_{2}}$ we assign a travel cost $c_{a_{i j t_{2}}}$ defined by:

$$
c_{a_{i j t_{2}}} \equiv \frac{\partial c_{i j t}\left(q_{i j t}\right)}{\partial q_{i j t}}, \quad i=1, \ldots, m ; j=1, \ldots, n ; t_{2}=t=1, \ldots, T,
$$

and with each link $j j^{\prime}$ we assign a travel cost defined by

$$
c_{a_{j j^{\prime} t_{2}}} \equiv \frac{\partial c_{j t}\left(h_{t}\right)}{\partial h_{j t}}, \quad j=1, \ldots, n ; j^{\prime}=1, \ldots, n ; t_{2}=t=1, \ldots, T,
$$

and with each link $j^{\prime} t_{2}\left(t_{2}+1\right)$ we assign a travel cost defined by

$$
c_{a_{j^{\prime} t_{2}\left(t_{2}+1\right)}} \equiv \frac{\partial c v_{j t}\left(u_{t}^{2}\right)}{\partial u_{j^{\prime} t}}, \quad j=1, \ldots, n ; j^{\prime}=1, \ldots, n ; t_{2}=t=1, \ldots, T-1 .
$$

Finally, for each link $a_{j^{\prime} k t_{3}}$ we assign a travel cost defined by

$$
c_{a_{j^{\prime} k t_{3}}} \equiv \hat{c}_{j k t}\left(Q_{t}^{2}\right), \quad j=1, \ldots, n ; j^{\prime}=1, \ldots, n^{\prime} ; k=1, \ldots, o ; t_{3}=t=1, \ldots, T
$$


Hence, a traveler traveling on path $p_{i t_{1} j t_{2} j^{\prime} k t_{3}}$ experiences a travel cost $C_{p_{i t_{1} j t_{2} j^{\prime} k t_{3}}}$ given by

$$
\begin{gathered}
C_{p_{i t_{1} t_{2} j^{\prime} k t_{3}}}=c_{a_{i t_{1}}}+\sum_{\tau=t_{1}}^{t_{2}-1} c_{a_{i \tau(\tau+1)}}+c_{a_{i j t_{2}}}+c_{a_{j j^{\prime} t_{2}}}+\sum_{\tau=t_{2}}^{t_{3}-1} c_{a_{j^{\prime} \tau(\tau+1)}}+c_{a_{j^{\prime} k t_{3}}} \\
=\sum_{\tau=1}^{T} \frac{\partial f_{i \tau}(q)}{\partial q_{i t_{1}}}+\sum_{\tau=t_{1}}^{t_{2}-1} \frac{\partial c v_{i t}\left(u_{\tau}^{1}\right)}{\partial u_{i \tau}}+\frac{\partial c_{i j t}\left(q_{i j t_{2}}\right)}{\partial q_{i j t_{2}}}+\frac{\partial c_{j t}\left(h_{t_{2}}\right)}{\partial h_{j t_{2}}}+\sum_{\tau=t_{2}}^{t_{3}-1} \frac{\partial c v_{j t}\left(u_{\tau}^{2}\right)}{\partial u_{j^{\prime} \tau}}+\hat{c}_{j k t}\left(Q_{t_{3}}^{2}\right) .
\end{gathered}
$$

Also, we define the travel demands associated with the O/D pairs as follows:

$$
d_{w_{k} t_{3}} \equiv d_{k t}, \quad k=1, \ldots, o ; t_{3}=t=1, \ldots, T
$$

and the travel disutilities:

$$
\lambda_{w_{k t_{3}}} \equiv \rho_{3 k t}, \quad k=1, \ldots, o ; t_{3}=t=1, \ldots, T
$$

Consequently, according to the elastic demand transportation network equilibrium conditions (21) and (22), we have that, for each O/D pair $w_{k t_{3}}$ in $\mathcal{G}_{\mathcal{S}}$ and every path connecting the $\mathrm{O} / \mathrm{D}$ pair $w_{k t_{3}}$, the following conditions must hold:

$$
\begin{aligned}
& C_{p_{i t_{1} j t_{2} j^{\prime} k t_{3}}}-\lambda_{w_{k t_{3}}}^{*}= \\
& \sum_{\tau=1}^{T} \frac{\partial f_{i \tau}\left(q^{*}\right)}{\partial q_{i t_{1}}}+\sum_{\tau=t_{1}}^{t_{2}-1} \frac{\partial c v_{i t}\left(u_{\tau}^{1 *}\right)}{\partial u_{i \tau}}+\frac{\partial c_{i j t}\left(q_{i j t_{2}}^{*}\right)}{\partial q_{i j t_{2}}}+\frac{\partial c_{j t}\left(h_{t_{2}}^{*}\right)}{\partial h_{j t_{2}}}+\sum_{\tau=t_{2}}^{t_{3}-1} \frac{\partial c v_{j t}\left(u_{\tau}^{2 *}\right)}{\partial u_{j^{\prime} \tau}}+\hat{c}_{j k t}\left(Q_{t_{3}}^{2 *}\right)-\lambda_{w_{k t_{3}}}^{*} \\
& \left\{\begin{array}{l}
=0, \quad \text { if } \quad x_{p_{i t_{1} t_{2} j^{\prime} k t_{3}}}^{*}>0, \\
\geq 0, \quad \text { if } \quad x_{p_{i t_{1} j t_{2} j^{\prime} k t_{3}}}^{*}=0
\end{array}\right.
\end{aligned}
$$

and

$$
\sum_{p \in P_{w_{k}}} x_{p_{i t_{1} t_{2} j^{\prime} k t_{3}}}^{*}\left\{\begin{array}{lll}
=d_{w_{k t_{3}}}\left(\lambda_{w t_{3}}^{*}\right), & \text { if } & \lambda_{w_{k} t_{3}}^{*}>0 \\
\geq d_{w_{k t_{3}}}\left(\lambda_{w t_{3}}^{*}\right), & \text { if } & \lambda_{w_{k} t_{3}}^{*}=0
\end{array}\right.
$$

We now provide the variational inequality formulation of the equilibrium conditions (47) and (48) in link form as in (24). According to Theorem 2, a link flow pattern $f^{*} \in \mathcal{K}^{4}$ is an equilibrium according to (47) and (48), if and only if it satisfies:

$$
\sum_{t_{1}=1}^{T} \sum_{i=1}^{m} c_{a_{i t_{1}}}\left(f^{1 *}\right) \times\left(f_{a_{i t_{1}}}-f_{a_{i t_{1}}}^{*}\right)+\sum_{t_{2}=1}^{T} \sum_{i=1}^{m} \sum_{j=1}^{n} c_{a_{i j t_{2}}}\left(f^{2 *}\right) \times\left(f_{a_{i j t_{2}}}-f_{a_{i j t_{2}}}^{*}\right)
$$




$$
\begin{aligned}
& +\sum_{t_{1}=1}^{T-1} \sum_{i=1}^{m} c_{a_{i t_{1}\left(t_{1}+1\right)}}\left(f^{3 *}\right) \times\left(f_{a_{i t_{1}\left(t_{1}+1\right)}}-f_{a_{i t_{1}\left(t_{1}+1\right)}}^{*}\right)+\sum_{t_{2}=1}^{T} \sum_{j=1}^{n} \sum_{j^{\prime}=1^{\prime}}^{n^{\prime}} c_{a_{j j^{\prime} t_{2}}}\left(f^{4 *}\right) \times\left(f_{a_{j^{\prime} t_{2}}}-f_{a_{j j^{\prime} t_{2}}}^{*}\right) \\
& +\sum_{t_{2}=1}^{T-1} \sum_{j^{\prime}=1}^{n^{\prime}} c_{a_{j^{\prime} t_{2}\left(t_{2}+1\right)}}\left(f^{5 *}\right) \times\left(f_{a_{j^{\prime} t_{2}\left(t_{2}+1\right)}}-f_{a_{j^{\prime} t_{2}\left(t_{2}+1\right)}^{*}}^{*}\right)+\sum_{t_{3}=1}^{T} \sum_{j^{\prime}=1}^{n^{\prime}} \sum_{k=1}^{n} c_{a_{j^{\prime} k t_{3}}}\left(f^{6 *}\right) \times\left(f_{a_{j^{\prime} k t_{3}}}-f_{a_{j^{\prime} k t_{3}}}^{*}\right) \\
& -\sum_{t_{3}=1}^{T} \sum_{k=1}^{o} \lambda_{w_{k} t_{3}}^{*} \times\left(d_{w_{k} t_{3}}-d_{w_{k} t_{3}}^{*}\right)+\sum_{t_{3}=1}^{T} \sum_{k=1}^{o}\left[d_{w_{k} t_{3}}^{*}-d_{w_{k} t_{3}}\left(\lambda_{w}^{*}\right)\right] \times\left[\lambda_{w_{k} t_{3}}-\lambda_{w_{k} t_{3}}^{*}\right] \geq 0, \quad \forall f \in \mathcal{K}^{4},
\end{aligned}
$$

which, through expressions (32) - (37), and (38) - (43) yields: determine

$$
\left(q^{*}, h^{*}, u^{1 *}, Q^{1^{*}}, u^{2 *}, Q^{2^{*}}, d^{*}, \rho_{3}^{*}\right) \in \mathcal{K}^{4}
$$

satisfying:

$$
\begin{gathered}
\sum_{t=1}^{T} \sum_{\tau=1}^{T} \sum_{i=1}^{m} \frac{\partial f_{i t}\left(q^{*}\right)}{\partial q_{i \tau}} \times\left[q_{i \tau}-q_{i \tau}^{*}\right]+\sum_{t=1}^{T} \sum_{i=1}^{m} \sum_{j=1}^{n} \frac{\partial c_{i j t}\left(q_{i j t}^{*}\right)}{\partial q_{i j t}} \times\left[q_{i j t}-q_{i j t}^{*}\right]+\sum_{t=1}^{T} \sum_{j=1}^{n} \frac{\partial c_{j t}\left(h_{t}^{*}\right)}{\partial h_{j t}} \times\left[h_{j t}-h_{j t}^{*}\right] \\
+\sum_{t=1}^{T} \sum_{i=1}^{m} \frac{\partial c v_{i t}\left(u_{i t}^{*}\right)}{\partial u_{i t}} \times\left[u_{i t}-u_{i t}^{*}\right]+\sum_{t=1}^{T} \sum_{j=1}^{n} \frac{\partial c v_{j t}\left(u_{j t}^{*}\right)}{\partial u_{j t}} \times\left[u_{j t}-u_{j t}^{*}\right] \\
+\sum_{t=1}^{T} \sum_{j=1}^{n} \sum_{k=1}^{o} \hat{c}_{j k t}\left(Q_{t}^{2 *}\right) \times\left[q_{j k t}-q_{j k t}^{*}\right]+\sum_{t=1}^{T} \sum_{k=1}^{o} \rho_{3 k t}^{*} \times\left[d_{k t}-d_{k t}^{*}\right] \\
+\sum_{t=1}^{T} \sum_{k=1}^{o}\left[d_{k t}^{*}-d_{k t}\left(\rho_{3 t}^{*}\right)\right] \times\left[\rho_{3 k t}-\rho_{3 k t}^{*}\right] \geq 0, \quad \forall\left(q, h, u^{1}, Q^{1}, u^{2}, Q^{2}, d, \rho_{3}\right) \in \mathcal{K}^{4} .
\end{gathered}
$$

But variational inequality (50) is precisely variational inequality (16) governing the multiperiod supply chain network equilibrium with elastic demands.

Hence, we have the following result:

\section{Theorem 3}

A solution $\left(q^{*}, h^{*}, u^{1 *}, Q^{1^{*}}, u^{2 *}, Q^{2^{*}}, d^{*}, \rho_{3}^{*}\right) \in \mathcal{K}^{4}$ of the variational inequality (16) governing the multiperiod supply chain network equilibrium coincides with the (via (32) - (37) and (38) - (43)) feasible link flow for the supernetwork $\mathcal{G}_{\mathcal{S}}$ constructed above and satisfies variational inequality (24); equivalently, variational inequality (50). Hence, it is a transportation network equilibrium according to Theorem 2. 


\section{Remark}

This supernetwork equivalence provides an interesting interpretation in terms of paths and path flows. A path corresponds to an end-to-end supply chain that may consist of various types of links, and spans not only the space but also the time periods. The links on a path may represent production, handling processes, transportation, and inventorying, which may be owned and operated by heterogenous entities. The cooperation between/among these entities makes the path flows feasible for serving the end-customers in the periods. The paths, or the end-to-end supply chains, however, dynamically influence and compete with one another. In the resultant equilibrium, at each period, all the active paths ending at a market have the same and minimum path cost. The paths with cost higher than the minimum are inactive.

Although in transportation networks a unique link flow solution may correspond to multiple possible path flow solutions, the results of our model, however, can provide clear and verifiable conditions under which a path (an end-to-end supply chain) can be active and be profitable. It elegantly and mathematically shows that the competition is actually between supply chains rather than between individual firms. It also helps decision-makers identify the set of possible active paths which can generate profits in equilibrium.

It is also worth noting that, in the case of a single period, the model collapses to a variant of the Nagurney et al. (2002) supply chain network equilibrium model, which was transformed into a transportation network equilibrium problem by Nagurney (2006a).

This modeling framework offers great modeling flexibility. For example, perishable products with a fixed lifetime $\mathcal{L}$ can be easily handled by removing all the paths with $t_{3}-t_{1}>\mathcal{L}$ from the reformulated transportation network. In addition, if there is a transportation delay $\mathcal{E}_{i j}$ between manufacturer $i$ and retailer $j$, we can simply modify Figure 1 by adding the transaction/transportation links from node $i t$ to node $j\left(t+\mathcal{E}_{i j}\right) ; t=1, \ldots, T-\mathcal{E}_{i j}$ and by removing the links from node $i t$ to node $j t ; t=1, \ldots, T$. One can easily see that the reformulation and computation can be adjusted accordingly without significant effort.

Finally, it is important to emphasize that existence and uniqueness results for the supply chain network model of Section 2 as well as stability and sensitivity analysis results, in terms of changes to the link cost and the demand price functions, can now be obtained directly through the transportation network equilibrium reformulation using the Theorems 
in Dafermos and Nagurney (1984b). In particular, Dafermos and Nagurney (1984b) provided conditions under which there exists a unique solution to the transportation network model which can be directly transferred to the multiperiod supply chain network model. If such conditions are not satisfied there may exist multiple solutions. In such a case, each solution is a possible Nash equilibrium among the supply chain firms, and can be interpreted economically.

\section{Multiperiod Supply Chain Network Examples with Computations}

In this section, we provide numerical examples to demonstrate how the theoretical results in this paper can be applied in practice. The algorithms used for the computations were coded in Matlab using a Dell laptop computer. We report the solutions in terms of link flows, rather than path flows, due to space limitations.

\section{The General Equilibration Algorithm}

In Examples 1 and 2 below, the multiperiod supply chain networks were first reformulated as the isomorphic elastic demand transportation networks. We then inverted the demand functions (since they were separable and this could easily be done), and transformed the elastic demand transportation networks into equivalent fixed demand transportation networks (see Gartner (1982) and Nagurney (1999)). The general equilibration algorithm (cf. Dafermos

and Sparrow (1969) and Nagurney (1999)) was then applied to compute the solutions of the fixed demand transportation networks. For the details of the general equilibration algorithm, we refer the audience to Dafermos and Sparrow (1969) and Nagurney (1999).

\section{Example 1}

The first example consisted of two manufacturers, two retailers, two demand markets, and three time periods, as depicted in Figure 3. Hence, in the first numerical example (see Figure 4), we had that: $T=3 ; m=2 ; n=2 ; n^{\prime}=2^{\prime}$, and $o=2$.

The production cost functions of the manufacturers were given by:

$$
f_{1 t}\left(q_{1 t}\right)=0.1 q_{1 t}^{2}+5 q_{1 t}+20, \quad t=1,2,3, \quad f_{2 t}\left(q_{2 t}\right)=0.15 q_{2 t}^{2}+4 q_{2 t}+10, \quad t=1,2,3 .
$$

The transaction/transportation cost functions faced by the manufacturers and associated 
Time Periods

$$
1
$$
2

Manufacturers

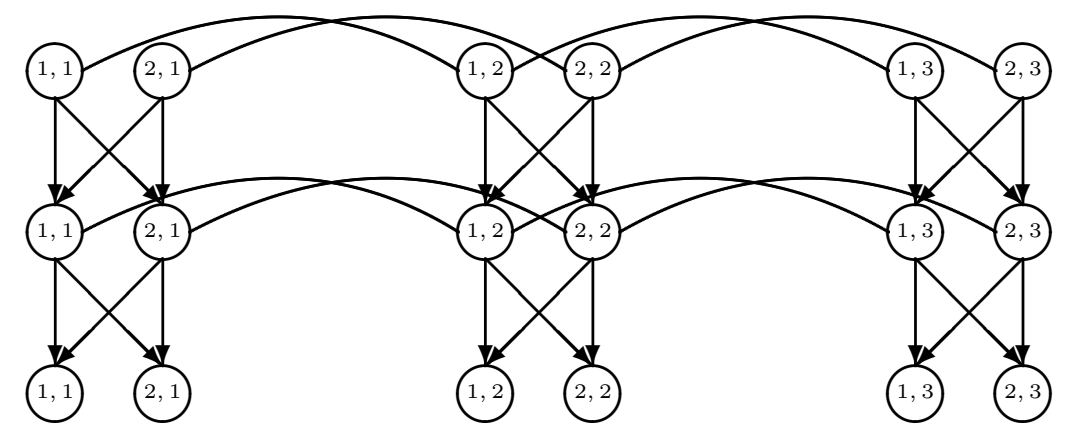

Retailers

Demand Markets

Figure 3: Multiperiod Supply Chain Network for Examples 1, 2, and 3

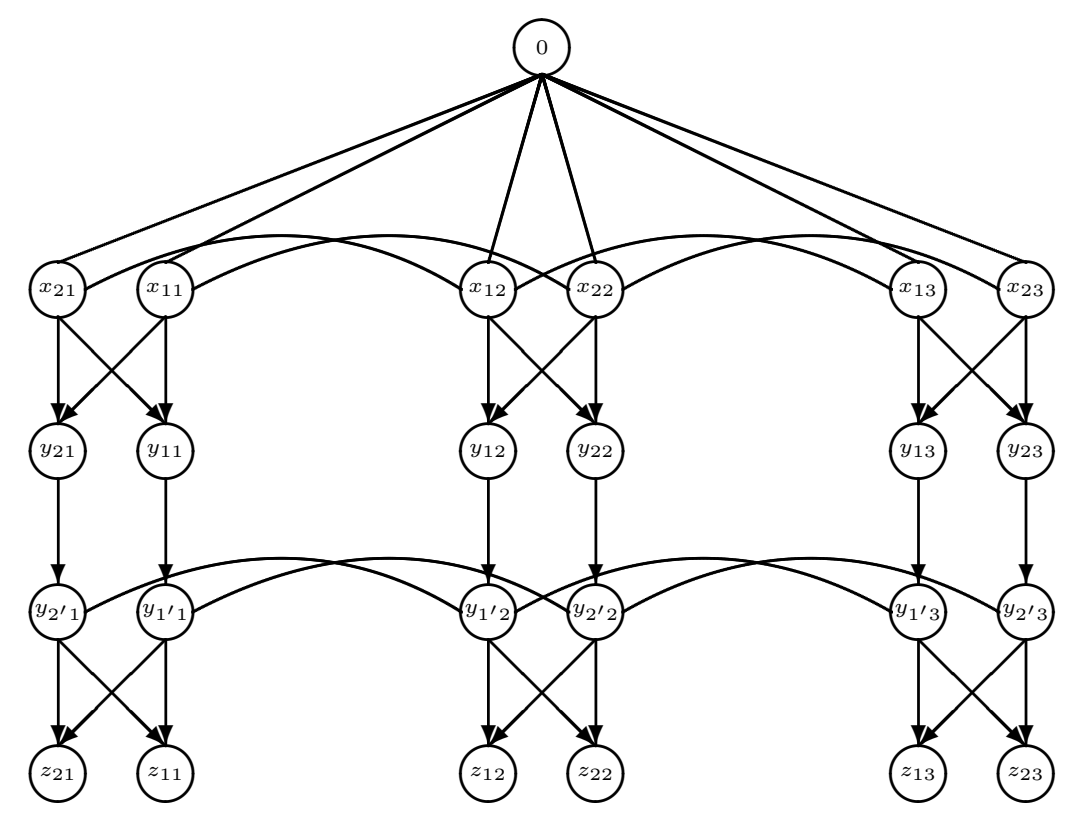

Figure 4: Supernetwork Structure of the Transportation Network Equilibrium Reformulation of Examples 1, 2, and 3 
with transacting with the retailers were:

$$
\begin{gathered}
c_{11 t}\left(q_{11 t}\right)=0.005 q_{11 t}^{2}+q_{11 t}, \quad c_{12 t}\left(q_{12 t}\right)=0.005 q_{12 t}^{2}+q_{12 t}, \\
c_{21 t}\left(q_{21 t}\right)=0.005 q_{21 t}^{2}+q_{21 t}, \quad c_{22 t}\left(q_{22 t}\right)=0.005 q_{22 t}^{2}+q_{22 t}, \quad t=1,2,3 .
\end{gathered}
$$

The handling costs of the retailers, in turn, were:

$$
c_{1 t}\left(h_{1 t}\right)=0.05 h_{1 t}^{2}+1.5 h_{1 t}+20, \quad t=1,2,3, \quad c_{2 t}\left(h_{2 t}\right)=0.1 h_{2 t}^{2}+h_{2 t}+30, \quad t=1,2,3 .
$$

The inventory cost functions of the manufacturers were given by:

$$
c v_{1 t}\left(u_{1 t}\right)=0.025 u_{1 t}^{2}+0.5 u_{1 t}+10, \quad t=1,2, \quad c v_{2 t}\left(u_{2 t}\right)=0.025 u_{2 t}^{2}+0.5 u_{2 t}+20, \quad t=1,2 .
$$

The inventory costs functions of the retailers were given by:

$$
c v_{1 t}\left(u_{1 t}\right)=0.025 u_{1 t}^{2}+0.5 u_{1 t}, \quad t=1,2, \quad c v_{2 t}\left(u_{2 t}\right)=0.025 u_{2 t}^{2}+0.5 u_{2 t}, \quad t=1,2 .
$$

Note that in the above cost functions, since the parameters of the quadratic terms were much smaller than those of the linear terms, the costs were approximately linear when the product flows were low and quadratic when the flows were high.

The unit transaction costs associated with transacting between the retailers and the demand markets were:

$$
c_{1 k t}=2, \quad k=1,2 ; t=1,2,3, \quad c_{2 k t}=1, \quad k=1,2 ; t=1,2,3 .
$$

The demand functions were given by:

$$
\begin{aligned}
& d_{11}\left(\rho_{311}\right)=15-\frac{1}{2} \rho_{311}, \quad d_{12}\left(\rho_{312}\right)=20-\frac{1}{3} \rho_{312}, \quad d_{13}\left(\rho_{313}\right)=80-\frac{1}{10} \rho_{313}, \\
& d_{21}\left(\rho_{321}\right)=10-\frac{1}{2} \rho_{321}, \quad d_{22}\left(\rho_{322}\right)=15-\frac{1}{3} \rho_{322}, \quad d_{23}\left(\rho_{323}\right)=90-\frac{1}{10} \rho_{323} .
\end{aligned}
$$

Note that the demands at both markets become less price-sensitive in the third time period.

The general equilibration method was utilized to compute the solution of the transportation network which was then translated into the equilibrium solution of the dynamic supply 
chain network as discussed in Section 3. We set the initial flows by equally distributing the demands among all the available paths. The algorithm converged after 481 iterations. The equilibrium prices at the manufacturers, $\rho_{1 i j t}^{*} ; i=1,2 ; j=1,2 ; t=1,2,3$, and at the retailers, $\rho_{2 j t}^{*} ; j=1,2 ; t=1,2,3$ were recovered from the above solution (see Appendix 1 for the computation).

The equilibrium solution for the transportation network equilibrium reformulation as well as the translation into the supply chain network equilibrium solution are given in Table 3 . In this example, there was inventorying at both manufacturers and at both retailers in time periods 1 and 2 .

\section{Example 2}

The second example had the same data as Example 1, except that the product was now assumed to be perishable with a lifetime $\mathcal{L}=2$. Thus, in this example, the products produced in the first period were not allowed to be in the market in the third period.

The multiperiod supply chain network problem was reformulated as a transportation network equilibrium model where the paths with $t_{3}-t_{1}>2$ were eliminated. We set the initial flows by equally distributing the demands among all the available paths. The equilibrium flow pattern was computed using the general equilibration method which converged after 532 iterations. We then translated the solution to the multiperiod supply chain flows and prices, as reported in Table 3 . The equilibrium prices, $\rho_{1 i j t}^{*} ; i=1,2 ; j=1,2: t=1,2,3$, and $\rho_{2 j t}^{*} ; j=1,2 ; t=1,2,3$ were also recovered and are shown in Table 3 . In this example, there was no inventorying of the product at the manufacturers from the first to the second time period.

We now further discuss and compare the results for Examples 1 and 2. First, since the demand for the product spiked and then became less price-sensitive in period 3, the prices at the demand markets in the third period increased to the highest level in both examples. Also, as we can expect, the market price of the perishable product was more volatile than that of the nonperishable product. Moreover, it was a little counter-intuitive to observe that for the perishable product, in the second period, the retailers paid $\$ 15.2808$ per unit to obtain the product from the manufacturers while selling the product to the consumers at $\$ 14.5485$ per unit. This interesting result actually make sense in this example, because 
in the second period, the product sold by the retailers was produced in period 1 and would expire before period 3, whereas the product that they purchased was produced in period 2 and could be sold at a high price of $\$ 23.7515$ at period 3 .

\section{The Euler Method}

In Examples 3 and 4, the multiperiod supply chain network problems were first reformulated as equivalent transportation network equilibrium problems, over the appropriately constructed supernetworks, as discussed in Section 3. They were then solved using the Euler method which was originally developed for the computation of transportation equilibria (cf. Nagurney and Zhang (1996) and the references therein). For the details of the Euler method, we refer the audience to Nagurney and Zhang (1996).

\section{Example 3}

The third example had the same network structure as Examples 1 and 2. The cost functions, however, were now nonseparable. The production cost functions of the manufacturers were given by:

$$
\begin{gathered}
f_{1 t}\left(q_{1 t}, q_{2 t}\right)=5+q_{1 t}+0.4 q_{1 t}^{2}+0.2 q_{1 t} q_{2 t}, \quad t=1,2,3 \\
f_{2 t}\left(q_{1 t}, q_{2 t}\right)=10+2 q_{2 t}+1.5 q_{2 t}^{2}+0.4 q_{1 t} q_{2 t}, \quad t=1,2,3 .
\end{gathered}
$$

The transaction/transportation cost functions faced by the manufacturer and associated with transacting with the retailers were:

$$
\begin{gathered}
c_{11 t}\left(q_{11 t}\right)=3 q_{11 t}+0.1 q_{11 t}^{2}, \quad c_{12 t}\left(q_{12 t}\right)=3 q_{12 t}+0.1 q_{12 t}^{2}, \\
c_{21 t}\left(q_{21 t}\right)=q_{21 t}+0.1 q_{21 t}^{2}, \quad c_{22 t}\left(q_{22 t}\right)=q_{22 t}+0.1 q_{22 t}^{2}, \quad t=1,2,3 .
\end{gathered}
$$

The handling costs of the retailers, in turn, were:

$c_{1 t}\left(h_{1 t}, h_{2 t}\right)=0.1 h_{1 t}^{2}+0.1 h_{1 t} h_{2 t}, \quad t=1,2,3, \quad c_{2 t}\left(h_{1 t}, h_{2 t}\right)=0.1 h_{2 t}^{2}+0.1 h_{1 t} h_{2 t}, \quad t=1,2,3$.

The inventory cost functions of the manufacturers were:

$$
c v_{1 t}\left(u_{1 t}\right)=0.2 u_{1 t}^{2}+u_{1 t}, \quad t=1,2, \quad c v_{2 t}\left(u_{2 t}\right)=0.5 u_{2 t}^{2}+2 u_{2 t}, \quad t=1,2 .
$$


Table 3: Equilibrium Solutions of Examples 1 and 2

\begin{tabular}{|l|l|l|l||l|l|l|}
\hline & & Example 1 & & & Example 2 & \\
\hline Variable & $t=1$ & $t=2$ & $t=3$ & $t=1$ & $t=2$ & $t=3$ \\
\hline$f_{a_{1 t}}^{*}=q_{1 t}^{*}$ & 32.6997 & 36.3997 & 40.5709 & 18.5877 & 45.5601 & 49.1646 \\
$f_{a_{2 t}}^{*}=q_{2 t}^{*}$ & 25.2589 & 27.7443 & 30.5455 & 15.7721 & 33.9027 & 36.3221 \\
\hline$f_{a_{11 t}}^{*}=q_{11 t}^{*}$ & 16.6645 & 21.3144 & 29.6492 & 11.2588 & 24.2616 & 33.5997 \\
$f_{a_{12 t}}^{*}=q_{12 t}^{*}$ & 11.2351 & 13.2002 & 17.6067 & 7.3289 & 16.8807 & 19.9826 \\
$f_{a_{21 t}}^{*}=q_{21 t}^{*}$ & 12.8955 & 16.9915 & 24.6881 & 9.8501 & 18.3844 & 27.2268 \\
$f_{a_{22 t}}^{*}=q_{22 t}^{*}$ & 7.4509 & 8.8588 & 12.6637 & 5.9219 & 11.0021 & 13.6114 \\
\hline$f_{a_{11^{\prime} t}}^{*}=h_{1 t}^{*}$ & 29.5601 & 38.3060 & 54.3373 & 21.1089 & 42.6460 & 60.8265 \\
$f_{a_{22^{\prime} t}}^{*}=h_{2 t}^{*}$ & 18.6860 & 22.0591 & 30.2705 & 13.2509 & 27.8829 & 33.5940 \\
\hline$f_{a_{1^{\prime} 1 t}}^{*}=q_{11 t}^{*}$ & 5.4186 & 12.8893 & 38.7451 & 6.4787 & 5.2527 & 46.0004 \\
$f_{a_{1^{\prime} 2 t}}^{*}=q_{12 t}^{*}$ & 0.9186 & 8.2277 & 56.0039 & 2.4797 & 6.8976 & 57.4722 \\
$f_{a_{2^{\prime} 1 t}}^{*}=q_{21 t}^{*}$ & 0.0000 & 0.1694 & 38.9204 & 0.8006 & 9.2310 & 31.4244 \\
$f_{a_{2^{\prime} 2 t}}^{*}=q_{22 t}^{*}$ & 0.0000 & 0.1643 & 31.7615 & 0.2996 & 2.9194 & 30.0525 \\
\hline$f_{a_{1 t(t+1)}}^{*}=u_{1 t}^{*}$ & 4.8001 & 6.6850 & & 0.0000 & 4.4177 & \\
$f_{a_{2 t(t+1)}}^{*}=u_{2 t}$ & 4.9124 & 6.8063 & & 0.0000 & 4.5162 & \\
\hline$f_{a_{1^{\prime} t(t+1)}}^{*}=u_{1 t}^{*}$ & 23.2227 & 40.4117 & & 12.1504 & 42.6460 & \\
$f_{a_{2^{\prime} t(t+1)}}^{*}=u_{2 t}^{*}$ & 18.6860 & 40.4114 & & 12.1505 & 27.8829 & \\
\hline$d_{w_{1} t}^{*}=d_{1 t}^{*}$ & 5.4186 & 13.0587 & 77.6655 & 7.2794 & 14.4838 & 77.4248 \\
$d_{w_{2} t}^{*}=d_{2 t}^{*}$ & 0.9186 & 8.3920 & 87.7655 & 2.7794 & 9.8171 & 87.5248 \\
\hline$\rho_{111 t}^{*}$ & 12.7065 & 13.4931 & 14.4106 & 9.8301 & 15.3546 & 16.1689 \\
$\rho_{121 t}^{*}$ & 12.7065 & 13.4931 & 14.4106 & 9.8301 & 15.3546 & 16.1689 \\
$\rho_{112 t}^{*}$ & 12.6523 & 13.4119 & 14.2903 & 9.7908 & 15.2808 & 16.0327 \\
$\rho_{122 t}^{*}$ & 12.6523 & 13.4118 & 14.2903 & 9.7908 & 15.2808 & 16.0327 \\
\hline$\rho_{21 t}^{*}$ & 17.1626 & 18.8237 & 21.3444 & 13.4410 & 14.5485 & 23.7515 \\
$\rho_{22 t}^{*}$ & 17.4438 & 18.8237 & 21.3444 & 13.4410 & 14.5485 & 23.7515 \\
\hline$\lambda_{w_{1} t}^{*}=\rho_{31 t}^{*}$ & 19.1626 & 20.8237 & 23.3443 & 15.4410 & 16.5485 & 25.7515 \\
$\lambda_{w_{2} t}^{*}=\rho_{32 t}^{*}$ & 18.1626 & 19.8237 & 22.3443 & 14.4410 & 15.5485 & 24.7515 \\
\hline
\end{tabular}


The inventory costs functions of the retailers were:

$$
c v_{1 t}\left(u_{1 t}\right)=0.05 u_{1 t}^{2}+u_{1 t}, \quad t=1,2, \quad c v_{2 t}\left(u_{2 t}\right)=0.02 u_{2 t}^{2}+u_{2 t}, \quad t=1,2 .
$$

The unit transaction costs associated with transacting between the retailers and the demand market were:

$$
c_{j k t}=1, \quad j=1,2 ; k=1,2 ; t=1,2,3 .
$$

The demand functions were given by:

$$
\begin{gathered}
d_{11}\left(\rho_{311}\right)=70-\rho_{311}, \quad d_{12}\left(\rho_{312}\right)=80-\rho_{312}, \quad d_{13}\left(\rho_{313}\right)=90-\rho_{313}, \\
d_{21}\left(\rho_{321}\right)=55-0.2 \rho_{321}, \quad d_{22}\left(\rho_{322}\right)=55-0.2 \rho_{322}, \quad d_{23}\left(\rho_{323}\right)=60-0.2 \rho_{323} .
\end{gathered}
$$

This multiperiod supply chain network problem was reformulated as a transportation network equilibrium problem with the supernetwork structure as depicted in Figure 4 . We initialized the algorithm by setting all flows equal to zero. The Euler method converged in 1, 803 iterations and computed the transportation network equilibrium flow and price pattern in Table 4, which was then translated into the equilibrium product flows and prices of the multiperiod supply chain network, also given in Table 4. In Example 3, cf. Table 4, there were no inventories held at the manufacturers.

\section{Example 4}

The last example had the same data as Example 3 except that we assumed that it now took one period of time to transport the product from manufacturer 1 to the retailers. We adjusted the multiperiod supply chain network in Figure 3 by first removing all the transaction links from manufacturer 1 and then adding the transaction links from manufacturer 1 at period $t$ to both retailers at period $t+1 ; t=1,2$. The modified supply chain network with transportation delay is shown in Figure 5.

The multiperiod supply chain network was transformed into the equivalent transportation network equilibrium problem as depicted in Figure 6. We initialized the problem by setting all flows equal to zero, and solved it using the Euler method, with convergence attained after 1, 048 iterations. The equilibrium solution, in transportation and supply chain notation, is given in Table 4. In Example 4, only the retailers had positive amounts of inventory and that was from the second to the last, that is, third, time period. 
Time Periods

1 2

Manufacturers

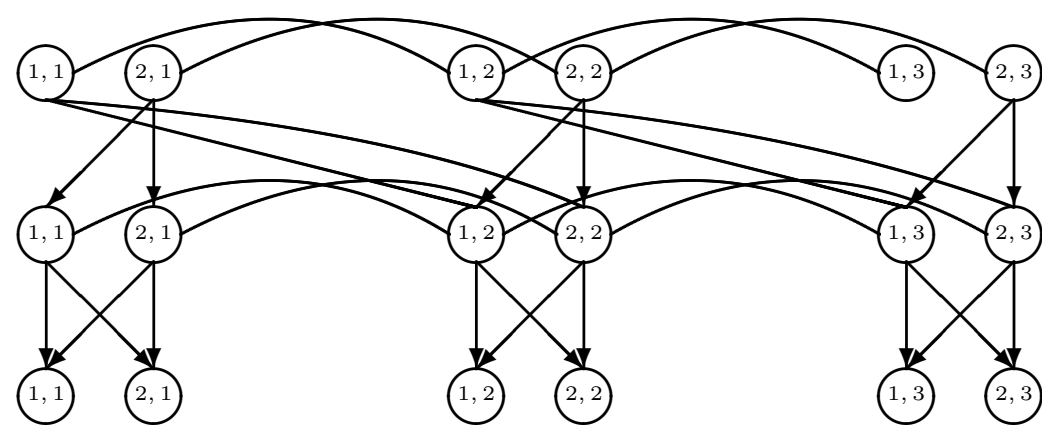

Demand Markets

Figure 5: Multiperiod Supply Chain Network for Example 4

Note that in Example 4, $q_{1 j t}^{*}$ now denotes the quantity of the product shipped from manufacturer 1 in period $t$ to retailer $j$ in period $t+1$.

In Example 3, since the first manufacturer had a lower production cost, he took most of the market share in the wholesale market. In Example 4, however, because of the transportation delay, the product produced by the first manufacturer could not arrive at the retailers in period 1, which led to a dramatic rise in the price at the demand markets in period 1. 
Table 4: Equilibrium Solutions of Examples 3 and 4

\begin{tabular}{|l|l|l|l||l|l|l|}
\hline & & Example 3 & & & Example 4 & \\
\hline Variable & $t=1$ & $t=2$ & $t=3$ & $t=1$ & $t=2$ & $t=3$ \\
\hline$f_{a_{1 t}}^{*}=q_{1 t}^{*}$ & 50.8291 & 51.9564 & 53.1257 & 49.4331 & 53.4121 & 0.0000 \\
$f_{a_{2 t}}^{*}=q_{2 t}^{*}$ & 9.1084 & 9.3028 & 9.5044 & 30.4517 & 9.7468 & 16.4581 \\
\hline$f_{a_{11 t}}^{*}=q_{11 t}^{*}$ & 25.4145 & 25.9782 & 26.5628 & 24.7165 & 26.7060 & 0.0000 \\
$f_{a_{12 t}}^{*}=q_{12 t}^{*}$ & 25.4145 & 25.9782 & 26.5628 & 24.7165 & 26.7060 & 0.0000 \\
$f_{a_{21 t}}^{*}=q_{21 t}^{*}$ & 4.5542 & 4.6514 & 4.7522 & 15.2258 & 4.8734 & 8.2290 \\
$f_{a_{22 t}}^{*}=q_{22 t}^{*}$ & 4.5542 & 4.6514 & 4.7522 & 15.2258 & 4.8734 & 8.2290 \\
\hline$f_{a_{11^{\prime}}}^{*}=h_{1 t}^{*}$ & 29.9688 & 30.6296 & 31.3150 & 15.2258 & 29.5900 & 34.9351 \\
$f_{a_{22^{\prime}}}^{*}=h_{2 t}^{*}$ & 29.9688 & 30.6296 & 31.3150 & 15.2258 & 29.5900 & 34.9351 \\
\hline$f_{a^{\prime} 1 t}^{*}=q_{11 t}^{*}$ & 2.3862 & 6.3799 & 14.7593 & 0.0000 & 7.6204 & 12.3561 \\
$f_{a_{\prime^{\prime} t}}^{*}=q_{12 t}^{*}$ & 21.2911 & 23.0842 & 24.0125 & 15.2258 & 20.8777 & 23.6708 \\
$f_{a_{2^{\prime} 1 t}}^{*}=q_{21 t}^{*}$ & 6.0551 & 10.8097 & 11.1321 & 0.0000 & 7.9223 & 12.1430 \\
$f_{a_{2^{\prime} t}}^{*}=q_{22 t}^{*}$ & 21.3970 & 19.3536 & 23.1657 & 15.2258 & 21.2307 & 23.2289 \\
\hline$f_{a_{1 t(t+1)}}^{*}=u_{1 t}^{*}$ & 0.0000 & 0.0000 & & 0.0000 & 0.0000 & \\
$f_{a_{2 t(t+1)}}^{*}=u_{2 t}^{*}$ & 0.0000 & 0.0000 & & 0.0000 & 0.0000 & \\
\hline$f_{a^{\prime} t(t+1)}^{*}=u_{1 t}^{*}$ & 6.2914 & 7.4568 & & 0.0000 & 1.0917 & \\
$f_{a_{2^{\prime} t(t+1)}}^{*}=u_{2 t}^{*}$ & 2.5165 & 2.9827 & & 0.0000 & 0.4368 & \\
\hline$d_{w_{1} t}^{*}=d_{1 t}^{*}$ & 8.4413 & 17.1897 & 25.8914 & 0.0000 & 15.5428 & 24.4991 \\
$d_{w_{2} t}^{*}=d_{2 t}^{*}$ & 42.6882 & 42.4379 & 46.3314 & 30.4517 & 42.1085 & 46.8998 \\
\hline$\rho_{111 t}^{*}$ & 51.5679 & 52.6213 & 53.7140 & 54.5801 & 54.0203 & \\
$\rho_{121 t}^{*}$ & 51.5679 & 52.6213 & 53.7140 & 54.5801 & 54.0203 & \\
$\rho_{112 t}^{*}$ & 51.5679 & 52.6213 & 53.7140 & 117.1736 & 54.5801 & 54.0203 \\
$\rho_{122 t}^{*}$ & 51.5679 & 52.6213 & 53.7140 & 117.1736 & 54.5801 & 54.0203 \\
\hline$\rho_{21 t}^{*}$ & 60.5586 & 61.8102 & 63.1085 & 121.7413 & 63.4571 & 64.5008 \\
$\rho_{22 t}^{*}$ & 60.5586 & 61.8102 & 63.1085 & 121.7413 & 63.4571 & 64.5008 \\
\hline$\lambda_{w_{1} t}^{*}=\rho_{31 t}^{*}$ & 61.5586 & 62.8102 & 64.1085 & 70.0000 & 64.4571 & 65.5008 \\
$\lambda_{w_{2} t}^{*}=\rho_{32 t}^{*}$ & 61.5586 & 62.8102 & 64.1085 & 122.7413 & 64.4571 & 65.5008 \\
\hline
\end{tabular}




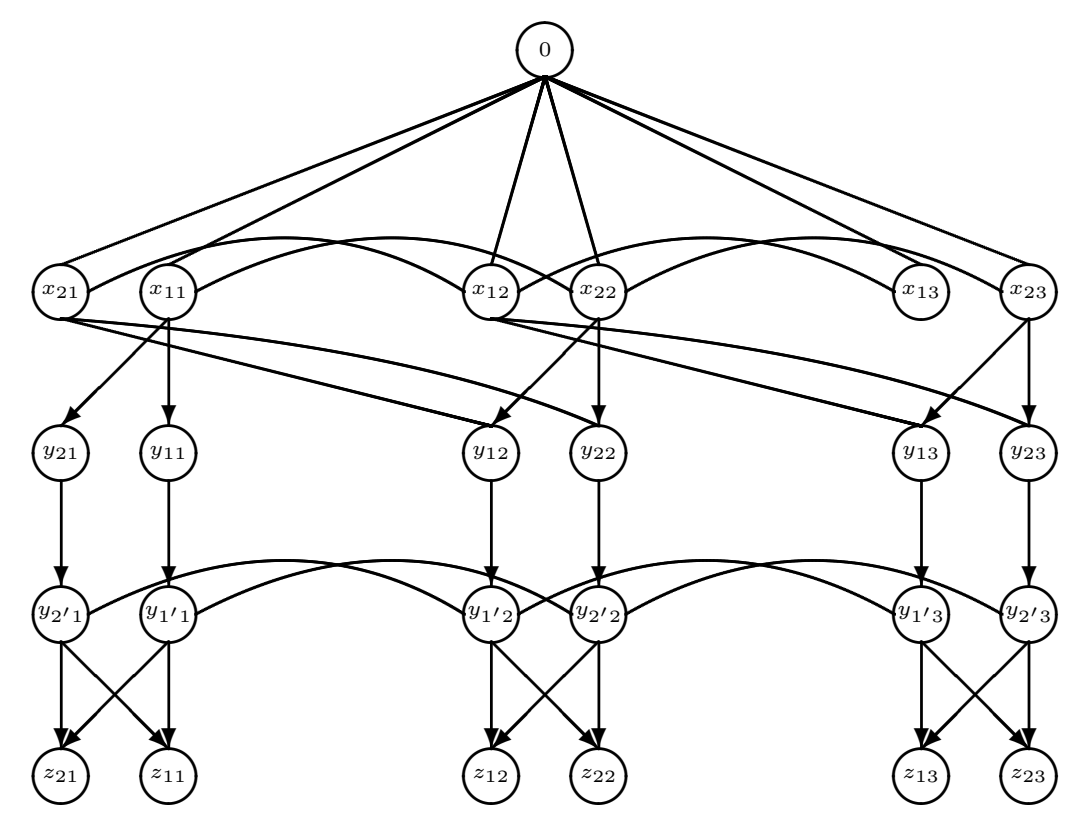

Figure 6: Supernetwork Structure of the Transportation Network Equilibrium Reformulation of Example 4

\section{Summary and Conclusions}

In this paper, we developed a multiperiod competitive supply chain network equilibrium model and demonstrated that it could be reformulated and solved as a transportation network equilibrium problem over a properly constructed abstract network or supernetwork. We assumed that the decision-makers in the multiperiod supply chain network had sufficient information of the future and sought the optimal plans that maximized their profits over the planning horizon. At the equilibrium, the prices at each period were mutually determined, and the optimality conditions of all the decision-makers held simultaneously so that no decision-maker could be better off by altering his decisions. This model allowed us to study the interplay of noncooperative decision-makers in a dynamic setting, and to compute the resultant equilibrium pattern of the prices, transactions, and inventories in the multiperiod supply chain network.

The supernetwork equivalence of the multiperiod supply chain network model provides an interesting interpretation of the equilibrium conditions in terms of paths and path flows. This supernetwork equivalence also allowed us to transfer some of the analytical and computational tools developed for transportation networks to the study of multiperiod supply chain equilibrium problems. 
In addition, we discussed how this framework could be used to capture both perishability of products and well as time delays associated with transportation through the appropriate changes in the underlying network topologies.

\section{Acknowledgments}

This research was supported, in part, by NSF Grant No. IIS-0002647 and, in part, by the John F. Smith Memorial Fund at the Isenberg School of Management. The authors are very grateful for this support.

The authors acknowledge the helpful comments and suggestions of two anonymous reviewers.

\section{References}

Aashtiani, M., and Magnanti, T.L., (1981) Equilibrium on a congested transportation network. SIAM Journal on Algebraic and Discrete Methods, vol.2, pp.213-216.

Anupindi, R., and Bassok, Y., (1996) Distribution channels, information systems and virtual centralization. In: Proceedings of the Manufacturing and Service Operations Management Society Conference, pp. 87-92.

Balkhi, Z.T., Benkherouf, L., (2004) On an inventory model for deteriorating items with stock dependent and time-varying demand rates. Computers and Operations Research, vol. 31 , pp. 223-240.

Bazaraa, M.S., Sherali, H.D., and Shetty, C.M., (1993) Nonlinear Programming: Theory and Algorithms. John Wiley \& Sons: New York.

Beckmann, M.J., McGuire, C.B., and Winsten, C.B., (1956) Studies in the Economics of Transportation. Yale University Press: New Haven, Connecticut.

Bernstein, F., and Federgruen, A., (2003) Pricing and replenishment stratgies in a distribution system with competing retailers. Naval Research Logistics, vol.51, pp.409-426.

Bhattacharjee, S., and Ramesh, R., (2000) A multi-period profit maximizing model for retail supply chain management: An integration of demand and supply-side mechanisms. 
European Journal of Operational Research, vol.122, no.3, pp.584-601.

Bramel, J., and Simchi-Levi, D., (1997) The Logic of Logistics: Theory, Algorithms and Applications for Logistics Management. Springer-Verlag: New York.

Boyce, D.E., Mahmassani, H.S., and Nagurney, A., (2005) A retrospective on Beckmann, McGuire, and Winsten's studies in the Economics of Transportation. Papers in Regional Science, vol.84, pp.85-103.

Cachon, G.P., and Netessine, S., (2003) In: Simchi-Levi D, Wu D, Shen Z-J (Eds), Game theory in supply chain analysis. In: Supply Chain Analysis in the eBusiness Era, Kluwer.

Cachon, G.P., and Zipkin, P.H., (1999) Competitive and cooperative inventory policies in a two-stage supply chain. Management Science, vol.45, pp.936-953.

Cachon, G., and Netessine. S., (2004) game theory in supply chain analysis, in supply chain analysis in The eBusiness era, D. Simchi-Levi, S. D. Wu, and M. Shen eds., Kluwer.

Chopra, S., and Meindl, P., (2009) Supply Chain Management: Strategy, Planning, and Operations (4th edition), Prentice Hall.

Cojocaru, M.G., Daniele, P., and Nagurney, A., (2006) Double-layered dynamics: a unified theory of projected dynamical systems and evolutionary variational inequalities. European Journal of Operational Research. vol.175, no.1, pp. 494-507.

Cojocaru, M.G., Daniele, P., and Nagurney, A., (2005) Projected dynamical systems and evolutionary variational inequalities via Hilbert spaces with applications. Journal of Optimization Theory and Applications, vol.127, no. 3, pp.549-563.

Corbett, C.J., and Karmarkar, U.S., (2001) Competition and structure in serial supply chains with deterministic demand. Management Science, vol.47, pp.966-978.

Coyle, J.J., Langley, C.J., Gibson, B., Novack, R.A., and Bardi, E., (2008) Supply Chain Management: A Logistics Perspective (8th edition). South-Western Cengage Learning, Mason, OH, USA.

Cruz, J.M., (2008) Dynamics of supply chain networks with corporate social responsibil- 
ity through integrated environmental decision-making. European Journal of Operational Research, vol. 184, no. 3, pp. 1005-1031.

Cruz, J.M., and Wakolbinger, T., (2008) Multiperiod effects of corporate social responsibility on supply chain networks,transaction costs,emissions, and risk. International Journal of Production Economics, vol.116, 61-74.

Dafermos, S., (1982) The general multimodal network equilibrium problem with elastic demand. Networks, vol.12, pp.57-72.

Dafermos, S., (1996) Isomorphic multiclass spatial price and multimodal traffic network equilibrium models. Regional Science and Urban Economics, vol.16, pp.197-209.

Dafermos, S., and Nagurney, A., (1984a) Sensitivity analysis for the general spatial economic equilibrium problem. Operations Research, 32, 1069-1086.

Dafermos, S., and Nagurney, A., (1984b) Stability and sensitivity analysis for the general network equilibrium - travel choice model. In: Volmuller J, Hamerslag R (Eds), Proceedings of the Ninth International Symposium on Transportation and Traffic Theory. VNU Science Press: Utrecht, The Netherlands, pp. 217-232.

Dafermos, S., and Nagurney, A., (1985) Isomorphism between spatial price and traffic network equilibrium problems. LCDS \# 85-17, Lefschetz Center for Dynamical Systems. Brown University, Providence, Rhode Island.

Dafermos, S., and Nagurney, A., (1987) Oligopolistic and competitive behavior of spatially separated markets. Regional Science and Urban Economics, 17, 245-254.

Dafermos, S., and Sparrow, F.T., (1969) The traffic assignment problem for a general network. Journal of Research of the National Bureau of Standards, vol.73B, 91-118.

Daniele, P., (2006) Dynamic Networks and Evolutionary Variational Inequalities. Edward Elgar Publishing, Cheltenham, England.

Demirtas, E.A. and Ustuna, O., (2009) Analytic network process and multi-period goal programming integration in purchasing decisions. Computers \& Industrial Engineering, vol.56, no.2, pp. 677-690. 
Dogan, K., and Goetschalckx, M., (1999) A primal decomposition method for the integrated design of multi-period production-distribution systems. IIE Transactions, vol.31, no.11, 1027-1036.

Federgruen, A., (1993) Centralized planning models for multi-echelon inventory systems under uncertainty. In: Graves SC, Rinooy Kan AHG, Zipkin P (Eds), Handbook in Operations Research and Management Science: Volume on Logistics of Production and Inventory. Elsevier: Amsterdam, pp. 133-137.

Federgruen, A., and Zipkin, P., (1986) An inventory model with limited production capacity and uncertain demands I: The average cost criterion. Mathematics of Operations Research, vol.11, pp.193-207.

Fisher, M., Ramdas, K., and Zhen, Y-S. (2001) Ending inventory valuation in multiperiod production scheduling. Management Science, vol.47, no. 5, pp. 679-692.

Fisk, C., and Boyce, D.E., (1983) Alternative variational inequality formulation of the network equilibrium-travel choice problem. Transportation Science, vol.17, pp.454-463.

Florian, M., and Hearn, D., (1995) Network equilibrium models and algorithms. In: Ball MO, Magnanti TL, Monma CL, Nemhauser, GL (Eds), Network Routing, Handbooks in Operations Research and Management Science 8. Elsevier Science: Amsterdam, The Netherlands, pp. 485-440.

Florian, M., and Klein, M., (1971) Deterministic production planning with concave costs and capacity constraints, Management Science, vol. 18, no. 1, pp. 12-20.

Friesz, T.L., Rigdon, M.A., and Mookherjee, R., (2006) Differential variational inequalities and shipper dynamic oligopolistic network competition. Transportation Research Part B: Methodological, vol. 40, no. 6, pp. 480-503.

Gabay, D., and Moulin, H., (1980) On the uniqueness and stability of Nash equilibria in noncooperative games. In: Bensoussan A, Kleindorfer P, Tapiero CS (Eds), Applied Stochastic Control in Econometrics and Management Science. North-Holland: Amsterdam, The Netherlands, pp. 271-294.

Ganeshan, R., Jack, E., Magazine, M.J., and Stephens P, 1998. A taxonomic review of 
supply chain management research. In: Tayur S, Magazine M, Ganeshan R (Eds), Quantitative Models for Supply Chain Management. Kluwer Academic Publishers: Boston, Massachusetts, pp. 531-574.

Gartner, N.H., (1980) Optimal traffic assignment with elastic demands, a review; part II: algorithmic apporaches. Transportation Science, vol.14, pp.192-209.

Geunes, J., and Pardalos, P.M., (2003) Network optimization in supply chain management and financial engineering: An annotated bibliography. Networks, vol.42, pp.66-84.

Hammond, D., and Beullensa, P., (2007) Closed-loop supply chain network equilibrium under legislation, , European Journal of Operational Research, vol. 183, no. 2, pp. 895-908.

Hensher, D., Button, K., and Brewer, S., (Eds), 2001. Handbook of Logistics and Supply Chain Management. Elsevier Science: Oxford, England.

Hsueh, C-F., and Chang M-S., (2008) Equilibrium analysis and corporate social responsibility for supply chain integration. European Journal of Operational Research, vol. 190, no. 1, pp. 116-129.

Hou, K-L., (2006) An inventory model for deteriorating items with stock-dependent consumption rate and shortages under inflation and time discounting. European Journal of Operational Research, vol. 168, pp. 463-474.

Kaminsky, P., and Swaminathan, J.M., (2004) Effective heuristics for capacitated production planning with multiperiod production and demand with forecast band refinement. Manufacturing \& Service Operations Management, vol. 6, no. 2, pp. 184 -194.

Kim, J-U., and Kim, Y-D., (2000) A Lagrangian relaxation approach to multi-period inventory/distribution planning. Journal of the Operational Research Society, vol.51, no.3, pp. 364-370.

Lederer, P.J., and Li, L., (1997) Pricing, production, scheduling, and delivery-time competition. Operations Research, vol.4, pp.407-420.

Lee, L., and Billington, C., (1993) Material management in decentralized supply chains. Operations Research, vol.41, pp.835-847. 
Leng M., and Parlar, M., (2005) Game Theoretic Applications In Supply Chain Management: A Review. INFOR, vol. 43, no. 3, pp. 187-220.

Liu, Z., and Nagurney, A., (2009) An integrated electric power supply chain and fuel market network framework: Theoretical modeling with empirical analysis for New England. Naval Research Logistics, vol.56, no.7, pp.600-624.

Mentzer, J.T. (Ed) (2001) Supply Chain Management. Sage Publishers: Thousand Oaks, California.

Miller, T.C., (2001) Hierarchical Operations and Supply Chain Planning. Springer-Verlag: London, England.

Nagarajana, M., and Soic, G., (2008) Game-theoretic analysis of cooperation among supply chain agents: Review and extensions. European Journal of Operational Research, vol.187, no. 3, pp.719-745.

Nagurney, A., (1999) Network Economics: A Variational Inequality Approach, second and revised edition. Kluwer Academic Publishers: Dordrecht, The Netherlands.

Nagurney, A., (2000) Sustainable Transportation Networks. Edward Elgar Publishing: Cheltenham, England.

Nagurney, A., (2006a) On the relationship between supply chain and transportation network equilibria: A supernetwork equivalence with computations. Transportation Research E, vol.42, pp.293-316.

Nagurney, A., (2006b) Supply Chain Network Economics: Dynamics of Prices, Flows, and Profits. Edward Elgar Publishing: Cheltenham, England.

Nagurney, A., and Aronson, J., (1988) A general spatial price equilibrium model: Formulation, solution, and computational results. Journal of Computational and Applied Mathematics, vol.22, pp.339-357.

Nagurney, A., and Aronson, J., (1989) A general dynamic spatial price network equilibrium model with gains and losses. Networks, vol.19, pp.751-769. 
Nagurney, A., Cruz, J., Dong, J., and Zhang, D., (2005) Supply chain networks, electronic commerce, and supply side and demand side risk. European Journal of Operational Research, vol.164, 120-142.

Nagurney, A., Dong, J., (2002) Supernetworks: Decision-Making for the Information Age. Edward Elgar Publishing: Cheltenham, England.

Nagurney, A., Dong, J., and Zhang, D., (2002) A supply chain network equilibrium model. Transportation Research E, vol.38, pp.281-303.

Nagurney, A, Liu, Z., Cojocaru, M., and Daniele, P., (2007) Dynamic electric power supply chains and transportation networks: An evolutionary variational inequality formulation. Transportation Research E: Logistics and Transportation Review, vol. 43, pp. 624-646.

Nagurney, A., and Zhang, D., (1996) Projected Dynamical Systems and Variational Inequalities with Applications. Kluwer Academic Publishers: Boston, Massachusetts.

Nash, J.F., (1950) Equilibrium points in n-person games. Proceedings of the National Academy of Sciences, vol.36, pp.48-49.

Nash, J.F., (1951) Noncooperative games. Annals of Mathematics, vol.54, pp.286-298.

Pang, J-S., and Stewart, D.E., (2008) Differential variational inequalities. Mathematical Programming, vol. 113, no. 2, pp. 345-424.

Pang, J-S., and Stewart, D.E., (2009) Solution dependence on initial conditions in differential variational inequalities. Mathematical Programming, vol.116, no.1-2, pp.429-460.

Patriksson, M., (1994) The Traffic Assignment Problems - Models and Methods. VSP: Utrecht, The Netherlands.

Perakis, G., and Sood, A., (2006) Competitive multi-period pricing for perishable products: a robust optimization approach. Mathematical Programming, vol.107, pp.295-335.

Porkka, P., Vepslinen, A.P.J., and Kuula, M., (2003) Multiperiod production planning carrying over set-up time. International Journal of Production Research, vol.41, no.6, pp. 1133-1148. 
See, C-T., and Sim, M., (2010) Robust approximation to multiperiod inventory management. Operations Research, vol.58, no.3, pp. 583-594.

Slats, P.A., Bhola, B., Evers, J.J., Dijkhuizen, G., (1995) Logistic chain modeling. European Journal of Operational Research, vol.87, pp.1-20.

Stadtler, H., Kilger, C. (Eds), (2000) Supply Chain Management and Advanced Planning. Springer-Verlag: Berlin, Germany.

Samuelson, P.A., (1952) Spatial price equilibrium and linear programming. American Economic Review, vol.42, pp.293-303.

Sen, A., (2008) The U.S. fashion industry: A supply chain review. International Journal of Production Economics, vol.114, no.2, pp. 571-593.

Takayama, T., and Judge, G.G., (1971) Spatial and Temporal Price and Allocation Models. North-Holland: Amsterdam, The Netherlands.

Walker, J., (1999) A model for determining price markdowns of seasonal merchandise. Journal of Product \& Brand Management, vol. 8, no. 4, pp. 352-361.

Yildirim, I., Tan, B., and Karaesmen, F., (2005). A multiperiod stochastic production planning and sourcing problem with service level constraints. OR Spectrum, vol. 27, no. 2-3, pp. 471-489.

Zhang, D., (2006) A network economic model for supply chain versus supply chain competition. Omega, vol. 34, pp. 283-95. 


\section{Appendix 1: Computation of the Equilibrium Prices at the Manufacturers and the Retailers}

We discuss how to recover the equilibrium prices $\rho_{2 j t}^{*} ; j=1, \ldots, n ; t=1, \ldots, T$, and $\rho_{1 i j t}^{*} ; i=1, \ldots, m ; j=1, \ldots, n$, and $t=1, \ldots, T$ from the solution of variational inequality (16). First, from (12), it follows that if $q_{j k t}^{*}>0$, then $\rho_{2 j t}^{*}=\rho_{3 k t}^{*}-\hat{c}_{j k t}\left(Q_{t}^{2 *}\right)$. In order to retrieve $\rho_{1 i j t}^{*}$, however, we need to substitute $h_{j t}$ using equation (7), and rewrite variational inequality (11) using the Lagrange multipliers as follows: determine $\left(Q^{1 *}, u^{2 *}, Q^{2 *}, \gamma_{2 j t}^{*}\right) \in \mathcal{K}^{2}$ satisfying:

$$
\begin{aligned}
& \sum_{t=1}^{T} \sum_{i=1}^{m} \sum_{j=1}^{n}\left[\frac{\partial c_{j t}\left(Q^{1 *}\right)}{\partial q_{i j t}}+\rho_{1 i j t}^{*}-\gamma_{2 j t}^{*}\right] \times\left[q_{i j t}-q_{i j t}^{*}\right]+\sum_{t=1}^{T} \sum_{j=1}^{n} \sum_{k=1}^{o}\left[\gamma_{2 j t}^{*}-\rho_{2 j t}^{*}\right] \times\left[q_{j k t}-q_{j k t}^{*}\right] \\
& +\sum_{t=1}^{T-1} \sum_{j=1}^{n}\left[\gamma_{2 j t}^{*}-\gamma_{2 j(t+1)}^{*}+\frac{\partial c v_{j t}\left(u_{j t}^{*}\right)}{\partial u_{j t}}\right] \times\left[u_{j t}-u_{j t}^{*}\right] \geq 0, \quad \forall\left(Q^{1}, u^{2}, Q^{2}, \gamma_{2}\right) \in R_{+}^{T n(m+o+2)},
\end{aligned}
$$

where $\gamma_{2}$ is $T n$-dimensional vector with components $\gamma_{2 j t} ; t=2, \ldots, T-1 ; j=1, \ldots, n$, denoting the Lagrange multipliers for constraint (9), $\gamma_{2 j 1} ; j=1, \ldots, n$, for constraint (8), and $\gamma_{2 j T} ; j=1, \ldots, n$, for constraint (10).

From the first summand of (60) it follows that if $q_{i j t}^{*}>0, \rho_{1 i j t}^{*}=\gamma_{2 j t}^{*}-\frac{\partial c_{j t}\left(Q^{1 *}\right)}{\partial q_{i j t}}=\gamma_{2 j t}^{*}-$ $\frac{\partial c_{j t}\left(h_{t}^{*}\right)}{\partial h_{t}}$. Thus, we need to retrieve the value of $\gamma_{2 j t}^{*}$ before recovering $\rho_{1 i j t}^{*}$. Since $q_{i j t}^{*}=f_{a_{i j t}}^{*}$ is greater than zero, according to (17), there must exist a path $\bar{p}$ that has positive path flow and contains link $a_{i j t}$. Without loss of generality, we denote path $\bar{p}$ by $p_{i t j \bar{t}_{2} \bar{j}^{\prime} \bar{k} \bar{t}_{3}}$ with path

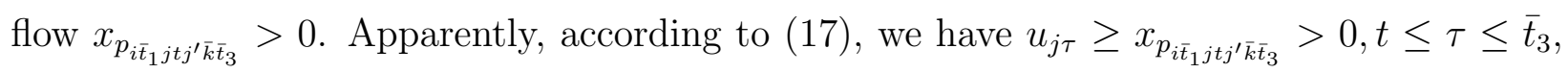

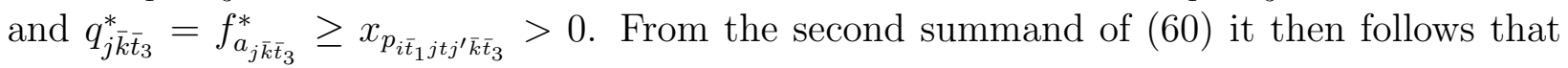
since $q_{\bar{k} \bar{t}_{3}}^{*}>0, \gamma_{2 j \bar{k} \bar{t}_{3}}=\rho_{2 j \bar{t}_{3}}=\rho_{3 \bar{k} \bar{t}_{3}}^{*}-\hat{c}_{j \bar{k} \bar{t}_{3}}\left(Q_{\bar{t}_{3}}^{2 *}\right)$. From the third summand of (60), we know

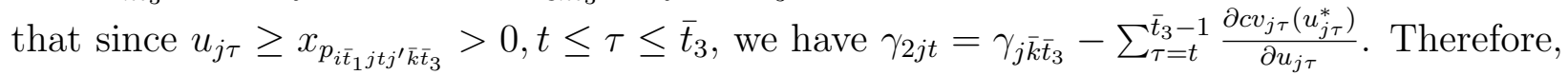
$\rho_{1 i j t}^{*}=\rho_{3 \bar{k} \bar{t}_{3}}^{*}-\hat{c}_{j \bar{k} \bar{t}_{3}}\left(Q_{\bar{t}_{3}}^{2 *}\right)-\sum_{\tau=t}^{\bar{t}_{3}-1} \frac{\partial c v_{j \tau}\left(u_{j \tau}^{*}\right)}{\partial u_{j \tau}}-\frac{\partial c_{j j}\left(Q^{1 *}\right)}{\partial q_{i j t}}$.

Note that the value of $\rho_{1 i j t}^{*}$ can be recovered from any active path that contains link $a_{i j t}$. Indeed, such a pricing mechanism is crucial and guarantees that the sum of (5), (11), and (15), which yields variational inequality (16), corresponds to an equilibrium in the sense of Definition 1. 